Marquette University

e-Publications@Marquette

School of Dentistry Faculty Research and

Publications

Dentistry, School of

6-15-2018

\title{
Dextran Hydrogels Incorporated with Bioactive Glass-Ceramic: Nanocomposite Scaffolds for Bone Tissue Engineering
}

\author{
Parisa Nikpour \\ University of Mazandran - Babolsar, Iran \\ Hamed Salimi-Kenari \\ University of Mazandaran - Babolsar, Iran \\ Farahnaz Fahimipour \\ Marquette University \\ Sayed Mahmood Rabiee \\ Babol Noshirvani University of Technology - Babol, Iran \\ Mohammad Imani \\ Iran Polymer and Petrochemical Institute
}

See next page for additional authors

Follow this and additional works at: https://epublications.marquette.edu/dentistry_fac

Part of the Dentistry Commons

\section{Recommended Citation}

Nikpour, Parisa; Salimi-Kenari, Hamed; Fahimipour, Farahnaz; Rabiee, Sayed Mahmood; Imani, Mohammad; Dashtimoghadam, Erfan; and Tayebi, Lobat, "Dextran Hydrogels Incorporated with Bioactive Glass-Ceramic: Nanocomposite Scaffolds for Bone Tissue Engineering" (2018). School of Dentistry Faculty Research and Publications. 267.

https://epublications.marquette.edu/dentistry_fac/267 


\section{Authors}

Parisa Nikpour, Hamed Salimi-Kenari, Farahnaz Fahimipour, Sayed Mahmood Rabiee, Mohammad Imani, Erfan Dashtimoghadam, and Lobat Tayebi 
Marquette University

\section{e-Publications@Marquette}

\section{Dentistry Faculty Research and Publications/School of Dentistry}

This paper is NOT THE PUBLISHED VERSION; but the author's final, peer-reviewed manuscript. The published version may be accessed by following the link in the citation below.

Carbohydrate Polymers, Vol. 190, June (2018): 281-294. DOI. This article is (C Elsevier and permission has been granted for this version to appear in e-Publications@Marquette. Elsevier does not grant permission for this article to be further copied/distributed or hosted elsewhere without the express permission from Elsevier.

\section{Dextran hydrogels incorporated with bioactive glass-ceramic: Nanocomposite scaffolds for bone tissue engineering}

Parisa Nikpour

Department of Chemical Engineering, Faculty of Engineering \& Technology, University of Mazandaran, Babolsar, Iran

Hamed Salimi-Kenari

Department of Chemical Engineering, Faculty of Engineering \& Technology, University of Mazandaran, Babolsar, Iran

Farahnaz Fahimipour

Marquette University School of Dentistry, Milwaukee, WI

Dental Biomaterials Department, School of Dentistry, Tehran University of Medical Sciences, Tehran, Iran 


\section{Sayed Mahmood Rabiee}

Department of Materials Engineering, Faculty of Mechanical Engineering, Babol Noshirvani University of Technology, Babol, Iran

\section{Mohammad Imani}

Department of Novel Drug Delivery Systems, Iran Polymer and Petrochemical Institute, Tehran, Iran Erfan Dashtimoghadam

Marquette University School of Dentistry, Milwaukee, WI

\section{Lobat Tayebi}

Marquette University School of Dentistry, Milwaukee, WI

Biomaterials and Advanced Drug Delivery Laboratory, School of Medicine, Stanford University, Palo Alto, CA

\footnotetext{
Abstract

A series of nanocomposite scaffolds comprised of dextran (Dex) and sol-gel derived bioactive glass ceramic nanoparticles (nBGC: 0-16 (wt\%)) were fabricated as bioactive scaffolds for bone tissue engineering. Scanning electron microscopy showed Dex/nBGC scaffolds were consisting of a porous 3D microstructure with an average pore size of $240 \mu \mathrm{m}$. Energy-dispersive $x$-ray spectroscopy illustrated $\mathrm{nBGC}$ nanoparticles were homogenously distributed within the Dex matrix at low nBGC content ( 2 wt\%), while agglomeration was observed at higher nBGC contents. It was found that the osmotic pressure and $n B G C$ agglomeration at higher nBGC contents leads to increased water uptake, then reduction of the compressive modulus. Bioactivity of Dex/nBGC scaffolds was validated through apatite formation after submersion in the simulated body fluid. Dex/nBGC composite scaffolds were found to show improved human osteoblasts (HOBs) proliferation and alkaline phosphatase (ALP) activity with increasing $n B G C$ content up to 16 (wt\%) over two weeks. Owing to favorable physicochemical and bioactivity properties, the Dex/nBGC composite hydrogels can be offered as promising bioactive scaffolds for bone tissue engineering applications.
} 


\section{Graphical abstract}

(A)
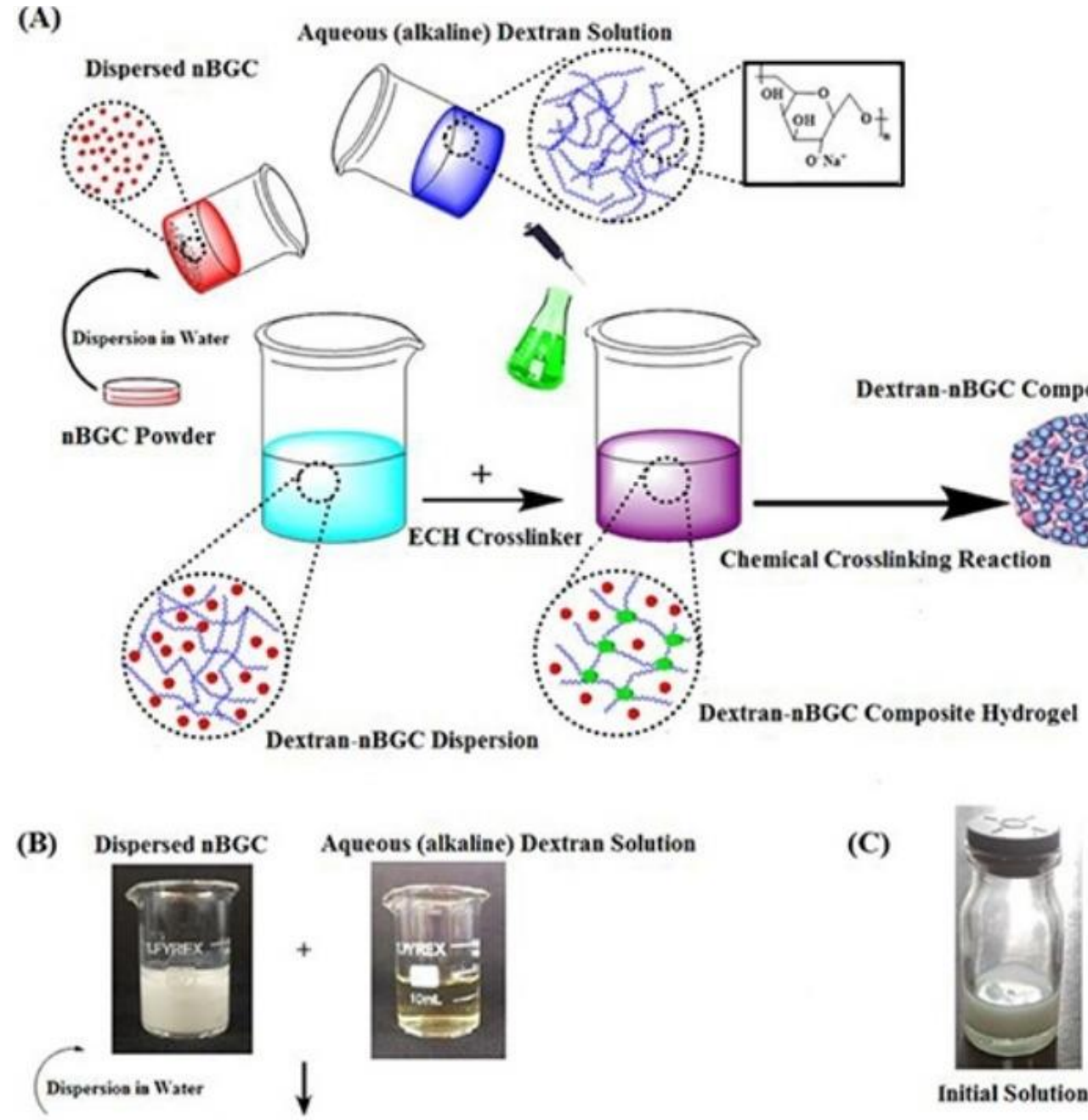

(C)
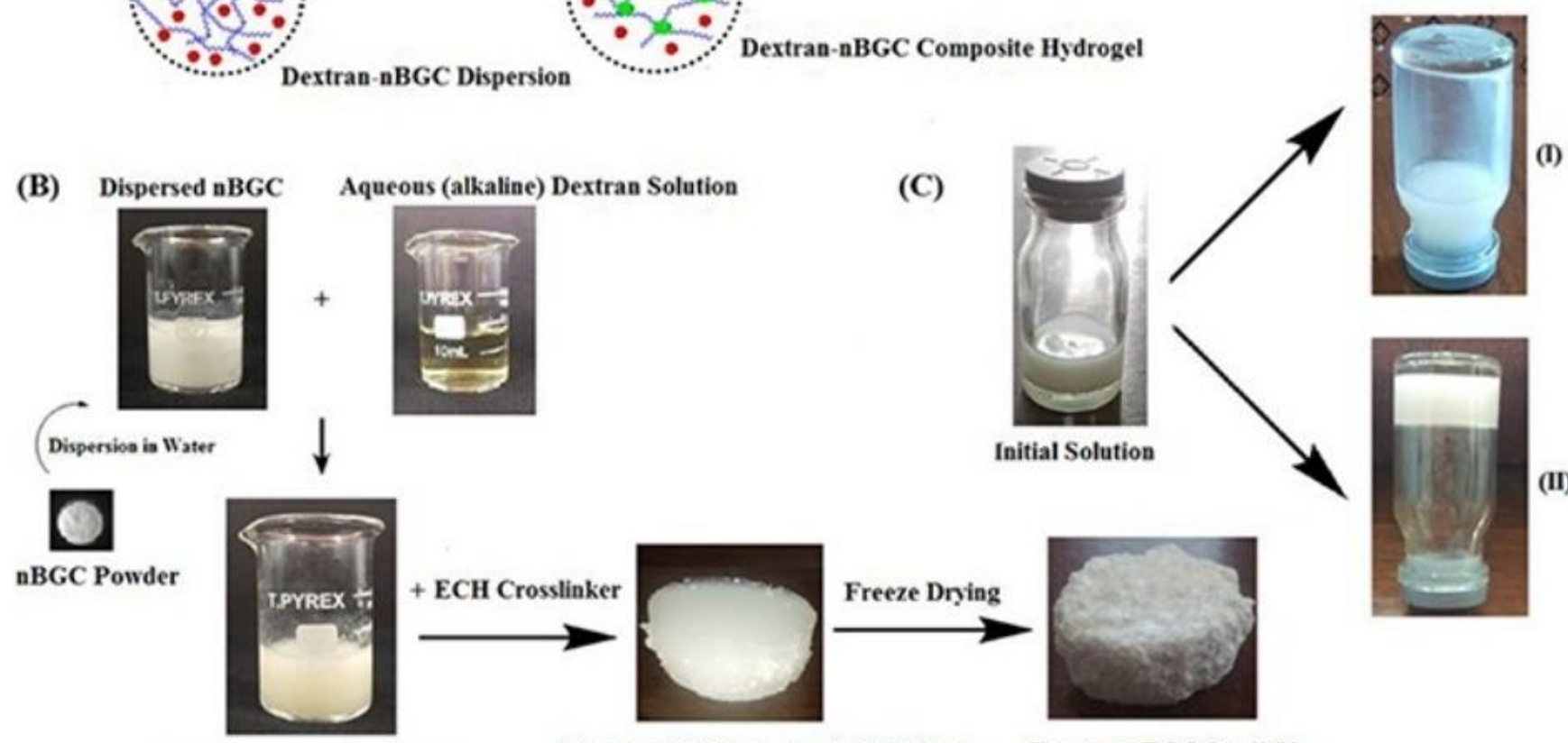

Dextran-nBGC Dispersion

Dextran-nBGC Composite Hydrogel
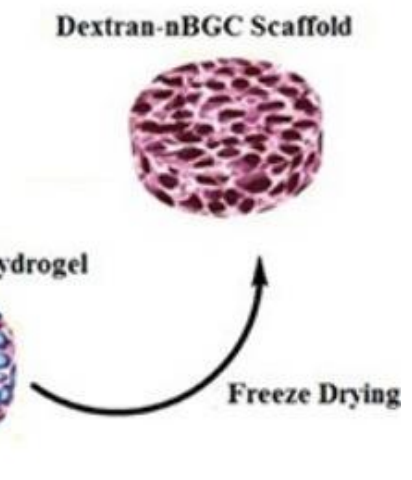

(I)
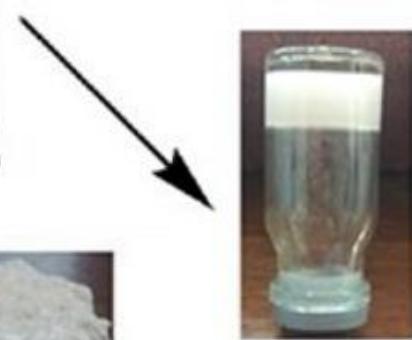

(II)

\section{Keywords}

Dextran, Hydrogel, Bioactive glass-ceramic, Nanocomposite, Bone tissue engineering

\section{Introduction}

There are many topics today that attract attention to bone tissue engineering, such as the everincreasing life expectancy, prevalence of bone defect and issues associated with biological grafts including extra surgery, increase the risk of morbidity, blood loss, sepsis and pain (in autografts) and increasing risk of rejection due to carrying histocompatibility antigens different from the host (in allografts and xenografts) (Horner et al., 2010). Bone tissue engineering, as an alternative therapeutic 
method for reconstructing native tissue inside the body, uses a temporary and porous 3D scaffold for the delivery and integration of cells and/or growth factors at the repair site (Khojasteh et al., 2017; Mozafari, Mehraien, Vashaee, \& Tayebi, 2012; Razavi et al., 2014). These scaffolds are usually fabricated from bioresorbable and bioactive materials, which have the potential to support and stimulate the regeneration of living tissue (Jazayeri et al., 2017; Razavi et al., 2014; Yazdimamaghani et al., 2013). Additionally, key characteristics for the scaffold design include biodegradability, biocompatibility, ideal mechanical properties and the ability not to produce any immunogenic responses in the body (O'brien, 2011). A variety of materials for the scaffold preparation have been reported, including metals(Yazdimamaghani et al., 2015), ceramics (Hench, 1991), and polymers, both natural and synthetic (Deepthi, Venkatesan, Kim, Bumgardner, \& Jayakumar, 2016; Dhandayuthapani, Yoshida, Maekawa, \& Kumar, 2011; Liu \& Ma, 2004; Patel, Bonde, \& Srinivasan, 2011; Yazdimamaghani et al., 2014). The corrosive nature of metals results in loosening of implants, corrosion products with unwanted side effects, high density and hardness compared with natural tissues, low biocompatibility, inactive connections with tissue, and allergic reactions, which make them unfavorable substitutes (Murugan \& Ramakrishna, 2005). Ceramics are fragile, have a low flexural strength and lack resiliency. These undesirable qualities of metals and ceramics attracted attention toward using other materials for tissue engineering purposes, including biodegradable polymers (e.g., polylactic acid), polysaccharides (e.g., chitosan, alginate, cellulose, hyaluronic acid and dextran) (Van Vlierberghe, Dubruel, \& Schacht, 2011) and proteins (e.g., elastin, collagen) (Jonker, Löwik, \& van Hest, 2012). In particular, polymeric hydrogels that are biocompatible and hydrophilic (Hoffman, 2012) are beneficial in various applications, specifically in medical fields to study cell growth for production of tissueequivalent constructs (Drury \& Mooney, 2003).

Among the natural polymers, dextran, a hydrophilic carbohydrate biopolymer that degrades in certain physical environments without any effect on the cell viability, has attracted attention in biological systems (Heinze, Liebert, Heublein, \& Hornig, 2006). Cross-linked dextran hydrogels (CDH) are known to provide favorable extracellular matrix (ECM) conditions with high water content and biocompatibility. However, some limitations to these hydrogels have also been demonstrated, such as poor mechanical properties, low load-bearing capacity and the ease of deformation, which restrict their use in applications of hard tissue engineering. The in vitro capacity of dextran for culture and proliferation of cells were reported previously (Deux et al., 2002; Fricain et al., 2013; Liu \& Chan-Park, 2009). Nevertheless, these cells were shown to attach and proliferate in clumps, rather than spreading onto the surface of the scaffolds, indicating the constricted capability of the pristine dextran to provide cell adhesion and spreading (Liu \& Chan-Park, 2009). In order to improve the bioactivity and obtain better mechanical properties, some inorganic materials, like hydroxyapatite (HA), has been incorporated with dextran matrix. Varoni et al. synthesized nanostructured hydroxyapatite-dextran composite scaffolds (Varoni et al., 2010), while Fricain et al. recently reported a nano-hydroxyapatitepullulan/dextran polysaccharide composite macroporous material for bone tissue engineering (Fricain et al., 2013).

Among inorganic materials, bioactive glass ceramics (BGC) containing $\mathrm{SiO}_{2}-\mathrm{CaO}-\mathrm{P}_{2} \mathrm{O}_{5}$ networks have gained much attention due to their biocompatibility, bioactivity and osteoconductive properties. Through the formation of surface hydroxy carbonate apatite (HCA) layer, these ceramic bonds to both hard and soft tissues (Lizzi et al., 2017; Salinas \& Vallet-Regí, 2013; Siqueira et al., 2017). Taking into account the previous art, bioactive glass ceramic affects the cell adhesion, proliferation, differentiation and colonization on the surface of implants (Kargozar et al., 2017; Shamsi et al., 2017; Wu, Wu, Xue, Li, 
\& Liu, 2017; Wu, Zhou, Chang, \& Xiao, 2013). Various composite hydrogels based on the bioactive glass have been synthesized recently, using biodegradable natural polymers including:

- $\alpha$-chitin/nBGC composite scaffolds (Peter et al., 2009).

- $\mathrm{nBGC}$ disseminated into chitosan matrix (Peter, Binulal, Soumya et al., 2010).

- Chitosan-gelatin/nBGC composite scaffolds for alveolar bone tissue (Peter, Binulal, Nair et al., 2010).

- Porous gelatin/BG for bone tissue engineering (Mozafari, Rabiee, Azami, \& Maleknia, 2010; Nadeem, Kiamehr, Yang, \& Su, 2013).

- Collagen hydrogels incorporated with surface-aminated mesoporous nBGC (El-Fiqi, Lee, Lee, \& Kim, 2013).

- $\quad$ nBGC-reinforced gellan-gum hydrogels for bone tissue engineering (Gantar et al., 2014).

To the best of our knowledge, $\mathrm{CDH}-\mathrm{nBGC}$ scaffolds for tissue engineering applications have not been reported before. The preparation of $\mathrm{CDH}-\mathrm{nBGC}$ scaffolds was carried out in this work to verify the possibility of improving the mechanical properties and the bioactivity of the dextran hydrogels using $\mathrm{nBGC}$ particles, such that it would extend the application range of the dextran to include bone tissue engineering. The reinforcement effect of $\mathrm{nBGC}$ particles was evaluated by the analysis of the microstructure, the mechanical properties and the ability to form HA in simulated body fluid. In addition, in vitro studies were performed by means of culturing normal human osteoblast (HOB) cells onto the composite scaffolds. To this end, the viability, morphology and alkaline phosphatase (ALP) activities were assessed in vitro for up to two weeks. We hypothesize that the fabricated biocompatible $\mathrm{CDH}-\mathrm{nBGC}$ constructs provide valuable scaffolding properties, such as favorable cell adhesion and proliferation, as well as enhanced mechanical properties.

\section{Materials and methods}

\subsection{Materials}

Dextran (Dex) (40000 $\mathrm{g} \mathrm{mol}^{-1}$ weight average molecular weight) was purchased from Pharmacosmos A/S, tetrahydrate $\left(\mathrm{Ca}\left(\mathrm{NO}_{3}\right)_{2} \cdot 4 \mathrm{H}_{2} \mathrm{O}\right)$ and triethyl phosphate $\left(\mathrm{C}_{6} \mathrm{H}_{15} \mathrm{O}_{4} \mathrm{P}\right)$ were purchased from Merck Chemicals, Dusseldorf, Germany. Nitric acid (>65\% purity) was purchased from Sigma-Aldrich, Steinheim, Germany. Simulated Body Fluid (SBF) was purchased from Pardis Pajhohesh, Yazd, Iran. Ethanol (>99\% purity) was purchased from Hamoon Teb Markazi Medicinal Chemical Industrial Co, Zarrandiyyeh, Iran. All chemicals were of analytical grade and used as supplied, without further purification. Deionized water (high-performance liquid chromatography grade) was prepared in-house using reverse osmosis technique (AquaMax 311, YoungLin Instruments, Anyang, South Korea) and used in the preparation of solutions.

\subsection{Synthesis of nano bioactive glass ceramic particles ( $\mathrm{nBGC}$ )}

Bioactive glass-ceramic (molar composition 64\% $\mathrm{SiO}_{2}-31 \% \mathrm{CaO}-5 \% \mathrm{P}_{2} \mathrm{O}_{5}$ ) was synthesized by a sol-gel method, as reported by Ravarian et al., with some modification (Ravarian et al., 2010). Briefly, $13.33 \mathrm{~g}$ $(0.064 \mathrm{~mol})$ of tetraethyl orthosilicate was added to $30 \mathrm{~mL}$ of $0.1 \mathrm{M}$ nitric acid; the solution was stirred for $30 \mathrm{~min}$ in order to complete the acid hydrolysis of TEOS. The following reagents were added in sequence, with about $45 \mathrm{~min}$ provided for each reagent to react thoroughly: $0.91 \mathrm{~g}(0.005 \mathrm{~mol})$ triethyl phosphate (TEP) and $7.32 \mathrm{~g}(0.031 \mathrm{~mol})$ of calcium nitrate tetrahydrate. To allow completion of the hydrolysis reaction, mixing was continued for $1 \mathrm{~h}$ after the last addition. The solution was cast in a cylindrical Teflon container and kept sealed for 10 days at room temperature to allow the hydrolysis 
and polycondensation reactions to take place until the gel was formed. The gel was kept in a sealed container and heated at $70{ }^{\circ} \mathrm{C}$ for 3 days. To remove the remaining water, a small hole was contrived in the lid to allow the leakage of gasses during heating of the gel to $120^{\circ} \mathrm{C}$ for 3 days. The dried gel was then heated for $24 \mathrm{~h}$ at $700{ }^{\circ} \mathrm{C}$ to first, stabilize the glass, and second, to eliminate the residual nitrate. The obtained glass after the thermal process was in the form of clumps of nanoparticles. Then, in order to decrease the size and suitable dispersion in dextran solution, milling operations were fixed for $5 \mathrm{~h}$ by a fast mill (FMD-2 M, Sanat Ceram, Iran). Alumina vial and balls were utilized. The process was performed at a ball-to-powder weight ratio (BPR) of 10:1. Absolute ethanol was used to prevent extensive agglomeration during the process.

\subsection{Preparation of the nanocomposite scaffolds}

CDH-nBGC composite scaffolds have been prepared via a chemical crosslinking technique previously reported by Imren et al. (Imren, Gümüşderelioğlu, \& Güner, 2006) with some modifications (Kenari, Alinejad, Imani, \& Nodehi, 2013; Kenari, Imani, Dashtimoghadam et al., 2013; Kenari, Imani, \& Nodehi, 2013). To this end, polymer solutions with a constant concentration ( $37.5 \mathrm{w} / \mathrm{v} \%$ ) were prepared by dissolving a specific amount of dextran in $1.2 \mathrm{M}$ sodium hydroxide aqueous solution. Different percentages of nBGC, specifically 2, 4, 6, 8 and $16 \mathrm{wt} \%$, were dispersed in distilled water then sonicated for $10 \mathrm{~min}$. The suspended $\mathrm{nBGC}$ were added to dextran solution and stirred (with a magnetic stirrer at $1200 \mathrm{rpm}$ for one hour) in order to prepare the CDH-nBGC composite. The resultant solution was subjected to sonication for $30 \mathrm{~s}$ to achieve a homogeneous dispersion. Epichlorohydrin (10 v/v\%) was added as a crosslinker. After $30 \mathrm{~s}$ of sonication, the resultant mixtures were poured into the containers and incubated in a convection oven for $24 \mathrm{~h}$ at $60^{\circ} \mathrm{C}$ for completion of the crosslinking reaction. The prepared $\mathrm{CDH}-\mathrm{nBGC}$ composite samples were taken out carefully and washed with distilled water to remove sodium hydroxide and unreacted agents such as excess dextran and $\mathrm{ECH}$. The resultant scaffolds were freeze-dried at $-48{ }^{\circ} \mathrm{C}$ and stored for further use. Fig. $1(\mathrm{~A}$ and $\mathrm{B})$ show the steps involved in the fabrication of $\mathrm{CDH}-\mathrm{nBGC}$ scaffolds. 
(A)

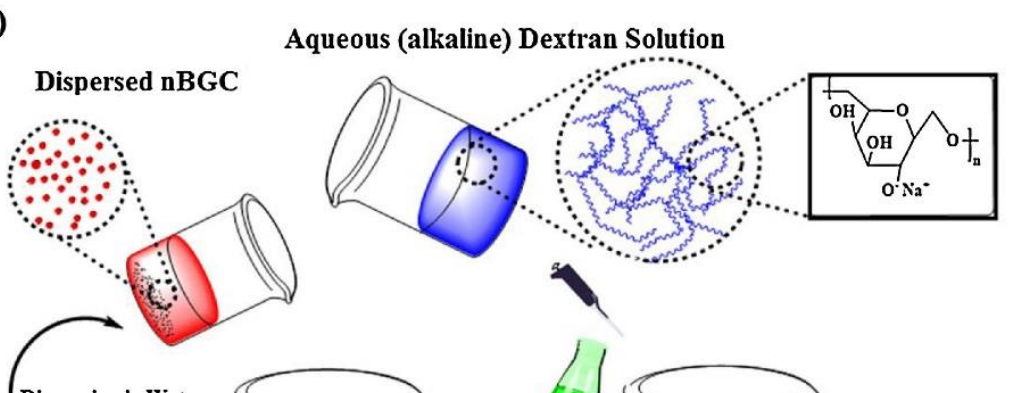

Dextran-nBGC Scaffold

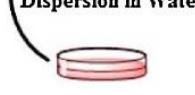

nBGC Powder
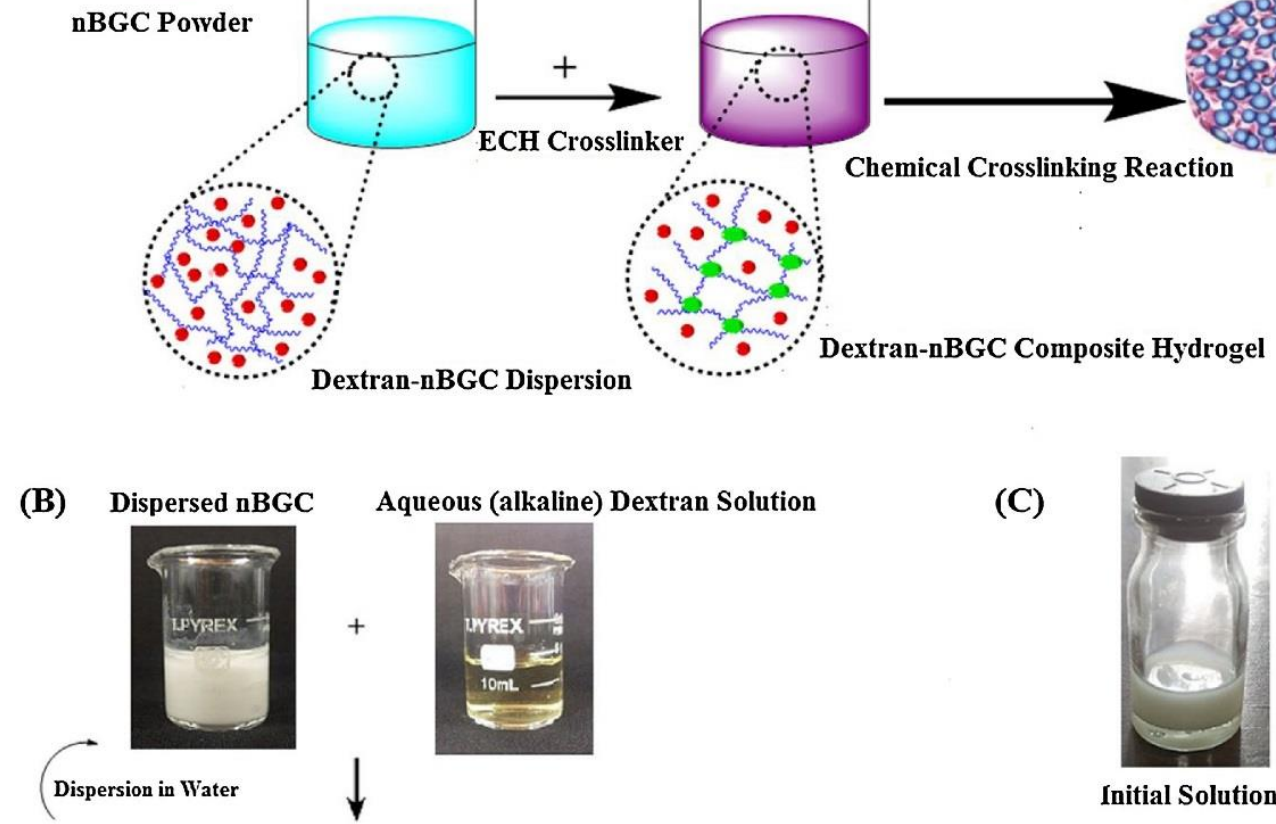

(C)
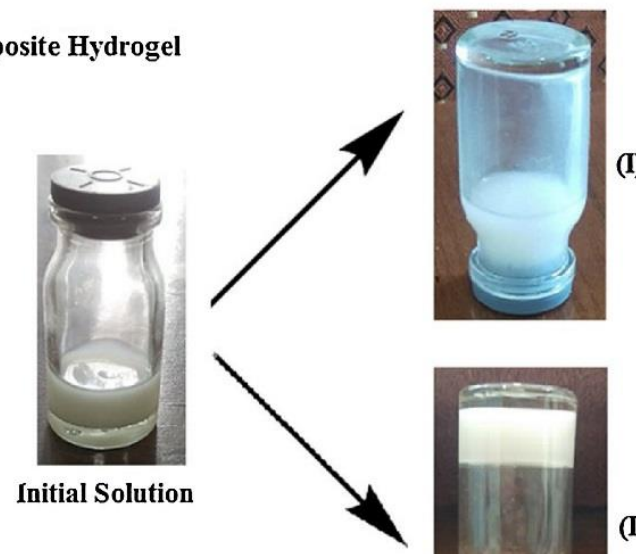

(l)
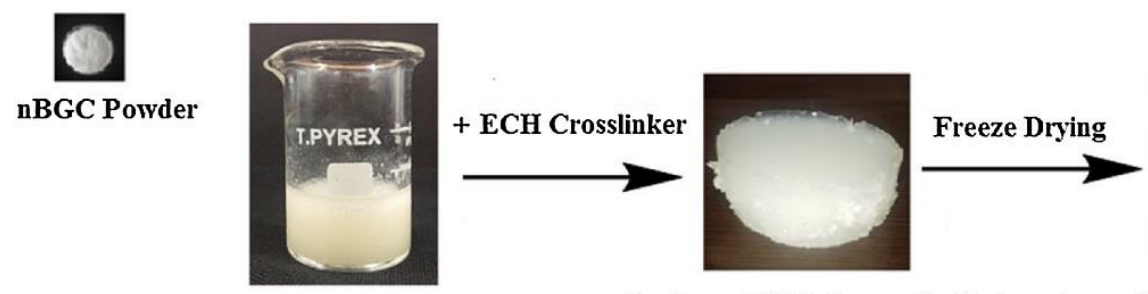

Dextran-nBGC Dispersion

Dextran-nBGC Composite Hydrogel
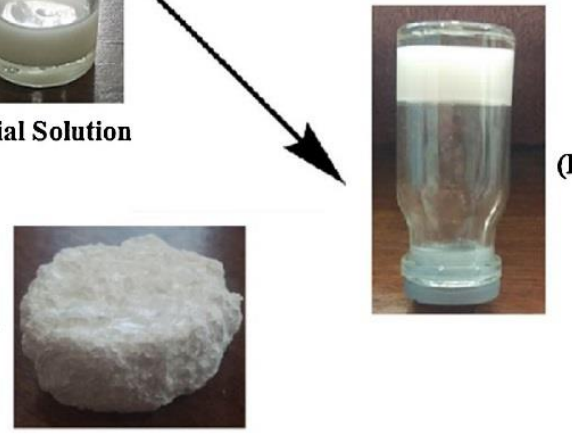

(II)

Fig. 1. Schematic illustration of fabrication of composite scaffolds (A), Visual aspect of the laboratory fabrication of CDH-nBGC composite scaffolds (B) and Visual aspect of the CDH-nBGC composite hydrogels at time before (I) and after (II) gelation (C).

\subsection{Structural characterizations}

\subsubsection{Fourier transform infrared spectroscopy (FTIR)}

The chemical bond structure and functional groups of the nBGC and nanocomposite scaffolds were examined by FTIR (TENSOR 27, Bruker, Germany) technique in the range between from 400 and $4000 \mathrm{~cm}^{-1}$ at $4 \mathrm{~cm}^{-1}$ resolution and 16 scans at room temperature. For FTIR analysis, dried nBGC and freeze-dried scaffolds were thoroughly grounded and mixed with potassium bromide $(\mathrm{KBr})$ at a specific ratio and pressed into pellets. 


\subsubsection{X-ray diffraction (XRD)}

The crystalline state of $\mathrm{nBGC}, \mathrm{CDH}$ and composite scaffolds were determined by $\mathrm{x}$-ray diffraction (XRD) spectrometry. XRD analysis was carried out by means of a diffractometer (D5000, Siemens, Germany) (Cu $\mathrm{k}_{\alpha}$ radiation) operating at a voltage of $40 \mathrm{kV}$ and $40 \mathrm{~mA}$, applying a scan step size of 0.02 at $2 \theta$ range $10-60^{\circ}$ and with a count rate of $1 \mathrm{~s}$ per step.

\subsubsection{Scanning electron microscopy (SEM)}

Morphology and particle size of nBGC specimens were assessed using Field Emission Scanning Electron Microscope (FESEM) (Mira 3 TESCAN-XMU, TESCAN, Czech Republic). The average size of the particles was determined by measuring the diameter of at least 100 randomly selected particles with Image J software. Also, the structural and surface morphology of the CDH-nBGC scaffolds were examined using Scanning Electron Microscopy (SEM) (VEGA, TESCAN, Czech Republic). To this end, the freeze-dried $\mathrm{CDH}-\mathrm{nBGC}$ scaffolds were cross-sectionally cut into thin sections using a razor blade. The sections were gold sputtered in vacuum (EMITECH, K450X, England) and examined using SEM at a voltage of $20 \mathrm{keV}$ in different magnification ratios. The average pore size was determined by measuring the size of at least 30 randomly selected pores. Energy-dispersive x-ray spectroscopy (EDX) analysis (VEGA, TESCAN, Czech Republic) was performed to investigate nBGC distribution.

\subsubsection{Thermal analysis}

Thermogravimetric analysis (TGA) (TGA II, Mettler Toledo, Switzerland) was utilized to investigate thermal behavior of $\mathrm{CDH}-\mathrm{nBGC}$ composite scaffolds. To analyze the probability of interactions occurring between Dex and $\mathrm{nBGC}$, TGA II instrument was operated at a heating rate of $10^{\circ} \mathrm{C} \mathrm{min}-1$ and a dynamic nitrogen atmosphere flowing at a rate of $50 \mathrm{~mL} \mathrm{~min}^{-1}$ at a temperature interval between ambient temperatures to $600^{\circ} \mathrm{C}$.

\subsubsection{Swelling studies}

The swelling studies were carried out on the nanocomposite scaffolds in distilled water at ambient conditions. The nanocomposite scaffolds were immersed in distilled water for 3 days. The surface water on the nanocomposite scaffolds was blotted using filter paper then weighed accurately. The equilibrium swelling ratio was determined using the following equation:

$E S R \%=\left(W_{0}-W_{w}\right) / W_{0} * 100$

\section{0}

W

\subsubsection{Mechanical properties}

The mechanical behavior of the composite scaffolds in a swollen state (ESR $=600 \%$ ) was investigated in compression mode, according to ASTM F-2150 (SMT-20, Santam, Iran). The cylindrical composite scaffolds measuring $4 \mathrm{~mm}$ height and $10 \mathrm{~mm}$ diameter were compressed between stainless steel plates using a $50 \mathrm{~N}$ load cell at a constant strain rate of $0.1 \mathrm{~mm} \mathrm{~min}^{-1}$ until failure. Tests were performed with a gauge length of $150 \mathrm{~mm}$. The compressive modulus was determined from the slope of the linear region of the stress-strain curves in the $0-40 \%$ strain range. Five replicates per sample were tested. 


\subsubsection{In vitro biomineralization studies}

The prepared scaffolds with equal weight and shape, including 2, 8 and 16 (wt\%) nBGC, were immersed in simulated body fluid (SBF) solution and incubated at $37{ }^{\circ} \mathrm{C}$ in closed falcon tubes for up to 28 days. Scaffolds were then removed, washed with distilled water to remove adsorbed minerals, and freezedried again. The surface of the samples was evaluated using SEM, EDX, FTIR and XRD analysis to trace the mineralization. Also, the size distribution of HA crystals on the surface of Dex-8(wt\%) nBGC after 28 days soaking in SBF, were determined by measuring the size of at least 50 selected crystals with Image J software.

\subsection{Biological characterizations}

The hydrogel scaffolds were sterilized through by three times immersion ethanol $(70 \%)$ and rinsed with PBS in 20 min cycles. The biological properties of the $\mathrm{CDH}$ and $\mathrm{CDH}$ containing 2, 8 and 16 (wt\%) nBGC was evaluated utilizing normal human osteoblasts (HOB, Cell Applications, USA). The HOB cells were seeded $\left(1 \times 10^{5}\right.$ cells $\left./ \mathrm{cm}^{2}\right)$ on the scaffold and cultured for 7 and 14 days.

\subsubsection{Immunofluorescent staining}

For immunofluorescent staining, hydrogel scaffolds were removed from the culture media, rinsed in PBS, fixed with $4 \%$ of glutaraldehyde and stained by CytoPainter F-actin Staining Kit-Green Fluorescence and DAPI (Abcam).

\subsubsection{PrestoBlue cell viability assay}

PrestoBlue cell viability assay (Invitrogen, USA) was performed according to the manufacturer's protocol at 7 and 14 days after cell culture. The fluorescence measurements (Ex: $560 \mathrm{~nm}$ and Em: $590 \mathrm{~nm}$ ) were measured by a spectrophotometric plate reader (Synergy HTX, BioTEK).

\subsubsection{ALP assay}

Alkaline phosphatase (ALP) activity of HOB cells cultured on hydrogel scaffolds was implemented utilizing an ALP assay kit (Abcam, USA). The lysates obtained from HOBs digestion were reacted with $p$ nitrophenyl phosphate ( $p$-NPP), and the absorbance of $p$-nitrophenol was determined at $405 \mathrm{~nm}$, employing a microplate reader (Synergy HTX, BioTEK) to indicate the ALP quantity.

\subsection{Statistical analysis}

All quantitative results were obtained from at least triplicate samples. Data was expressed as mean \pm SD $(n=5)$. Statistical analysis was carried out using Student's two-tailed $t$ test. A value of $p<0.05$ was considered to be statistically significant.

\section{Results and discussion}

\subsection{Structural analysis of the CDH-nBGC scaffolds}

A simple and ordinary way to confirm the formation of nanocomposite scaffolds is to invert the container, as shown in Fig. 1(C). The initial solution can flow in the container, while after the gelation behaves like a solid material. The molecular structure, chemical composition of the resulting CDH-nBGC scaffolds and its mechanical properties must be addressed by the crosslinking reaction mechanism and probable interactions occurring between Dex and nBGC particles. Under alkaline conditions, the reaction of $\mathrm{ECH}$ and soluble dextran chains follows the nucleophilic substitution mechanism known as 
Williamson synthesis (Fig. 2( $\left.A_{1}\right)$ ), previously described by Salimi-Kenari et al. (Kenari, Imani et al., 2013). The addition of ECH to dextran chains in an aqueous alkaline medium is a molecular reaction occurring via formation of a Dex- $\mathrm{O}^{-} \mathrm{Na}^{+}$intermediate stage. The fragments formed can be easily transformed to the epoxy ring by dehydrochlorination in the presence of $\mathrm{NaOH}$. Dehydrochlorination reaction between two macromolecules containing $\mathrm{OH}$ and $\mathrm{Cl}$-substitutes, respectively, is recognized, providing formation of crosslinking structure. During the described crosslinking mechanism, the addition of $\mathrm{nBGC}$ to the dextran solution can have some effects. The $\mathrm{Ca}^{2+}$ ions which are loosely bound to the silica structure, could be released out of it upon mixing nBGC with dextran solution, and have a role in the physically crosslinking process. These $\mathrm{Ca}^{2+}$ ions could act through the formation of partially ionic or coordinate bonds as a chelating center between four residues functional hydroxyl groups (Dex$\mathrm{O}^{-}$) of neighboring dextran chains, resulting in the formation of a three- dimensional network, as shown in Fig. 2( $\left.A_{2}\right)$.

(A) $\left(\mathbf{A}_{1}\right)$

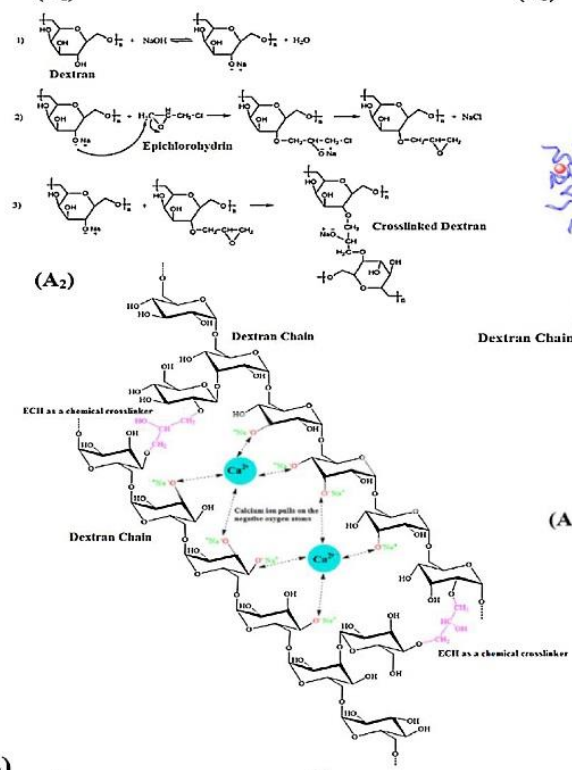

(B)

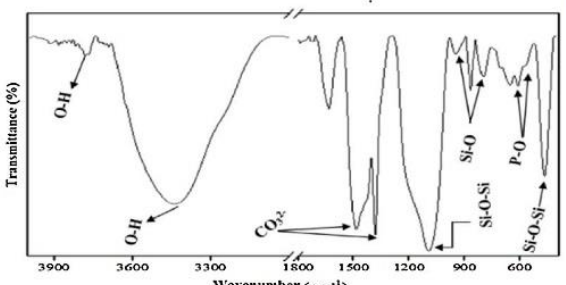

(C)

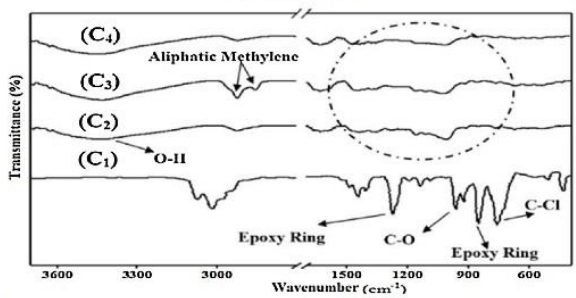

(A)

(A4)

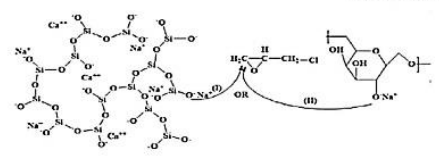

(E)

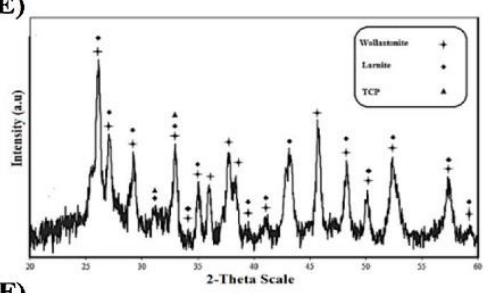

(F)

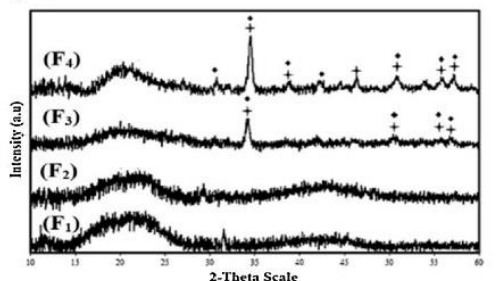

(D)
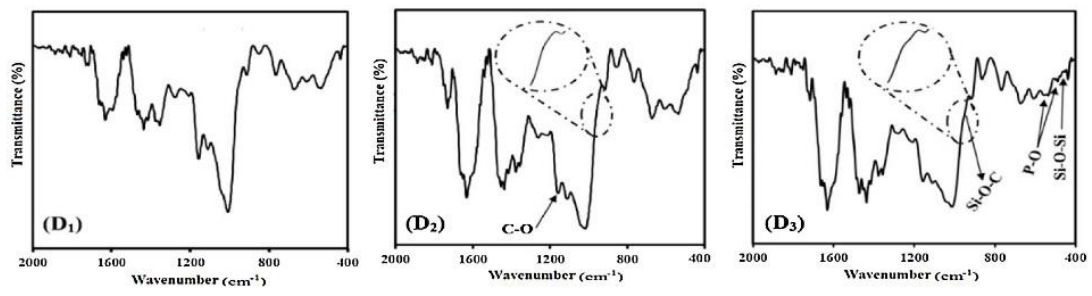
Fig. 2. Proposed mechanism for the reaction of ECH with dextran (Kenari, Alinejad et al., 2013; Kenari, Imani, Dashtimoghadam et al., 2013; Kenari, Imani et al., 2013, Salimi-Kenari, Mollaie, Dashtimoghadam, Imani, \& Nyström, 2018) $\left(A_{1}\right)$, the released $\mathrm{Ca}^{2+}$ as a physical crosslinker along with $\mathrm{ECH}$ in nanocomposite scaffolds $\left(A_{2}\right)$, nBGC particles as active fillers in Dex matrixe $\left(A_{3}\right)$ and possible reaction of $n B G C$ with ECH $\left(A_{4}\right)$. FT-IR spectra of $\operatorname{nBGC}(B), E C H\left(C_{1}\right)$, virgin dextran $\left(C_{2}, D_{1}\right), C D H\left(C_{3}, D_{2}\right)$ and $C D H-8\left(\right.$ wt\%) nBGC nanocomposite $\left(C_{4}, D_{3}\right)$. XRD pattern of $n B G C(E), C D H\left(F_{1}\right), C D H-2(w t \%) n B G C\left(F_{2}\right), C D H-8(w t \%) n B G C\left(F_{3}\right)$ and $C D H-16(w t \%) n B G C\left(F_{4}\right)$ nanocomposites.

The formation of a relatively good interface between the $\mathrm{nBGC}$ particles and polymer matrixes is vital, as this parameter largely determines the mechanical and degradation properties of the composite hydrogels. Hence, the introduction of $\mathrm{nBGC}$, as an inorganic bioactive filler into dextran matrix, imparts strength and bioactivity while keeping the positive properties of the polymer such as flexibility and capacity to deform under loads. The larger specific surface area of the nanoparticles could lead also to increased interface effects and contribute to forming an active hybrid layer on dextran chains, resulting in improved mechanical properties, as shown in Fig. 2(A $A_{3}$. Blaker et al. (Blaker, Maquet, Boccaccini, Jérôme, \& Bismarck, 2005) similarly reported the interaction between Bioglass and biodegradable polymers.

It is worth to note that, according to proposed the nucleophilic substitution mechanism during the crosslinking reaction, it would be possible $\mathrm{Si}-\mathrm{O}^{-} \mathrm{Na}^{+}$functionality of $\mathrm{nBGC}$ compete with Dex $-\mathrm{O}^{-} \mathrm{Na}^{+}$ residual functional group of dextran chains in the nucleophilic reaction with $\mathrm{ECH}$ molecules. Regardless this scenario, the efficiency of chemical crosslinking reaction of $\mathrm{ECH}$ would be limited in the presence of bioglass charged ions (Fig. 2(A $\left(A_{4}\right)$ ).

Fourier transform infrared (FTIR) analysis was done to identify the atomic structure of the composite scaffolds and confirm the results of other analysis as a supplementary study. FT-IR spectra of nBGC, virgin dextran, $\mathrm{ECH}$ molecules, $\mathrm{CDH}$ and $\mathrm{CDH}-8$ (wt\%) nBGC scaffold are presented in Fig. 2(B)-(D). As shown in Fig. 2(B), the significant bonds of $\mathrm{nBGC}$ are predominantly related to $\mathrm{Si} \_\mathrm{O}$ vibration mode. The peaks positioned at 470,798, 954 and $1087 \mathrm{~cm}^{-1}$ are related to the silicate network and attributed to the $\mathrm{Si} \_\mathrm{O} \_$Si bending mode, $\mathrm{Si} \_\mathrm{O}$ symmetric stretching of bridging oxygen atoms between tetrahedrons, $\mathrm{Si} \_\mathrm{O}$ stretching of non-bridging oxygen atoms and $\mathrm{Si}$ _ O__ Si asymmetric stretching, respectively (Mami et al., 2008; Mansur \& Costa, 2008; Roman, Padilla, \& Vallet-Regi, 2003). The bands located at 576 and $617 \mathrm{~cm}^{-1}$ are attributed to $\mathrm{P} \_\mathrm{O}$ amorphous and crystal bands in $\mathrm{PO}_{4}{ }^{3-}$ tetrahedron, respectively (Filgueiras, La Torre, \& Hench, 1993; Mozafari et al., 2010). The observed peaks at 1380 and $1390 \mathrm{~cm}^{-1}$ represent the presence of $\mathrm{CO}_{3}{ }^{-2}$ ions in $\mathrm{nBGC}$ composition (Coates, 2000; Mačković et al., 2012). Additionally, the bands at 3446 and $3782 \mathrm{~cm}^{-1}$ confirm the presence of hydroxyl groups in nBGC structure. The FT-IR spectrum of virgin dextran (Fig. 2( $\left.C_{2}\right)$ ) exhibited one characteristic spectral band at $3444 \mathrm{~cm}^{-1}$, which corresponds to the secondary hydroxyl groups. The peaks at 2919 and $2860 \mathrm{~cm}^{-1}$, were attributed to the aliphatic methylene functional groups, showed an increase in their intensities due to more methylene groups introduced by ECH into the hydrogel structure. The appearance of a new absorption band at $1167 \mathrm{~cm}^{-1}$ (Fig. $\left.2\left(D_{2}\right)\right)$ corresponds to the stretching $C_{-} \mathrm{O}$ bands, and the remarkable decrease in the intensity of epoxy ring at $853 \mathrm{~cm}^{-1}$ and $1269 \mathrm{~cm}^{-1}$ rather than $\mathrm{ECH}, 956 \mathrm{~cm}^{-1}$ (C_O stretching), and $753 \mathrm{~cm}^{-1}$ (C_Cl stretching) supports the formation of new bonds due to the crosslinking reaction (Imren et al., 2006; Kenari, Alinejad et al., 2013; Kenari, Imani, Dashtimoghadam et al., 2013; Kenari, Imani et al., 2013; Salimi-Kenari, Imani, Nodehi, \& Abedini, 2016). For CDH-8 (wt\%) nBGC composite scaffolds (Fig. 2(C4)), FT-IR spectra show a reduction in peak intensity at 2919 and $2860 \mathrm{~cm}^{-1}$ when compared to $\mathrm{CDH}$, indicating the $\mathrm{nBGC}$ effect on $\mathrm{ECH}$ performance as a chemical crosslinker, according to the proposed mechanism in Fig. 2( $\left.\mathrm{A}_{4}\right)$. The 
observed peak at $950 \mathrm{~cm}^{-1}$ (Si_____ bond) (Al-Oweini \& El-Rassy, 2009) in FTIR spectra of CDH-8 (wt\%) nBGC scaffold (Fig. 2(D $\left.D_{3}\right)$ which is absent in CDH scaffolds (Fig. 2( $\left.D_{2}\right)$ ) can confirm the proposed mechanism. In general, composite scaffolds showed the combined peaks of CDH and nBGC. However, detailed evaluation in 400-2000 cm $\mathrm{cm}^{-1}$ range in Fig. 2(D) reveals the presence of three peaks at 472,491 and $560 \mathrm{~cm}^{-1}$, which are absent in $\mathrm{CDH}$ and can correspond to Si_O__Si bond (Mami et al., 2008; Mansur \& Costa, 2008; Roman et al., 2003) and P-O vibration, respectively. These peaks also confirm the presence of nanoparticles (Filgueiras et al., 1993; Mozafari et al., 2010).

The possible presence and crystal structure of crystalline phases in $\mathrm{nBGC}$ particles are evaluated by XRD analysis. XRD patterns of the milled nBGC and CDH-nBGC scaffolds is represented in Fig. 2(E) and (F). As shown in Fig. 2(E), nBGC has an amorphous-crystalline state. The peaks match the pattern of Wollastonite $\mathrm{CaSiO}_{3}$ (JCPDS \#27-0088) and Larnite $\mathrm{Ca}_{2} \mathrm{SiO}_{4}$ (JCPDS\#33-0302). As observed, these two phases have overlapped in more angels (20). Also, the presence of $\alpha$-TCP phase is reasonable due to the existence of phosphate and silicate groups in bioglass structure. According to Tamjid et al. (Tamjid, Bagheri, Vossoughi, \& Simchi, 2011), mechanical milling can affect glass structure and formation of $\mathrm{CaSiO}_{3}$ crystals in the bioactive glass structure. The XRD diffraction pattern of $\mathrm{CDH}$ also indicates a broad peak positioned between 14.84 and $27.15^{\circ}(2 \theta)$, which confirms its general amorphous state (Fig. $2\left(F_{1}\right)$ ). Due to the lower concentration of nBGC in the nanocomposite containing 2 (wt\%) nanoparticles, masked with polymer phase (Fig. $2\left(F_{2}\right)$ ), no certain sharp peak can be seen and a general amorphous structure was observed. By increasing the amount of $\mathrm{nBGC}$, some sharp peaks at certain (20) angles appeared (such as $35^{\circ}, 50^{\circ}, 56^{\circ}$ and $57^{\circ}$ ), which can be attributed to Wollastonite and Larnite crystalline phases. Lack or reduction of some peaks with high intensity in the nanocomposite scaffolds at $(2 \theta)$ angles of $12^{\circ}, 27^{\circ}, 28^{\circ}, 96^{\circ}, 24^{\circ}$ and $68^{\circ}$, in comparison to $\mathrm{nBGC}$, can be due to the more polymeric phase which can mask crystalline structures of dispersed nanoparticles. Also high water content of the samples can cause dissolution of crystalline phases, however, the low solubility of calcium silicate crystals in water and alkaline condition weakens this effect. It should be noted that the intensity of the observed peaks in XRD analysis does not show phase content in the composition.

\subsection{Morphological characterization of $n B G C$ and $C D H-n B G C$ scaffolds}

Fig. 3(A, B) shows the FESEM micrographs of nBGC particles after mechanical milling, producing nanoparticles with a mean size of $58 \mathrm{~nm}$. A histogram corresponding to nanoparticles size distribution is represented in Fig. 3(D), indicating the range of nBGC size is predominantly between 32 and $89 \mathrm{~nm}$. Due to the high specific surface area and surface energy of $n B G C$, the nanoparticles tend to aggregate and form larger nBGC clusters (Fig. 3(A)) in the range of 47-2000 nm (with an average size of $735 \mathrm{~nm}$ ) presented in the histogram in Fig. 3(C). The EDX spectra of the prepared nBGC particles (Fig. 3(E)) and mapping of $\mathrm{Ca}, \mathrm{P}, \mathrm{Si}$ and $\mathrm{O}$ elements (Fig. 3(F)) depict the peaks of these elements and their qualitative abundance, respectively. The atomic ratio and weight percent of Si:Ca:P:O are presented in Table inside Fig. 3(E). It is notable, SEM images of BGC particles before mechanical milling as shown in Fig. S1 on Supplementary material section. 

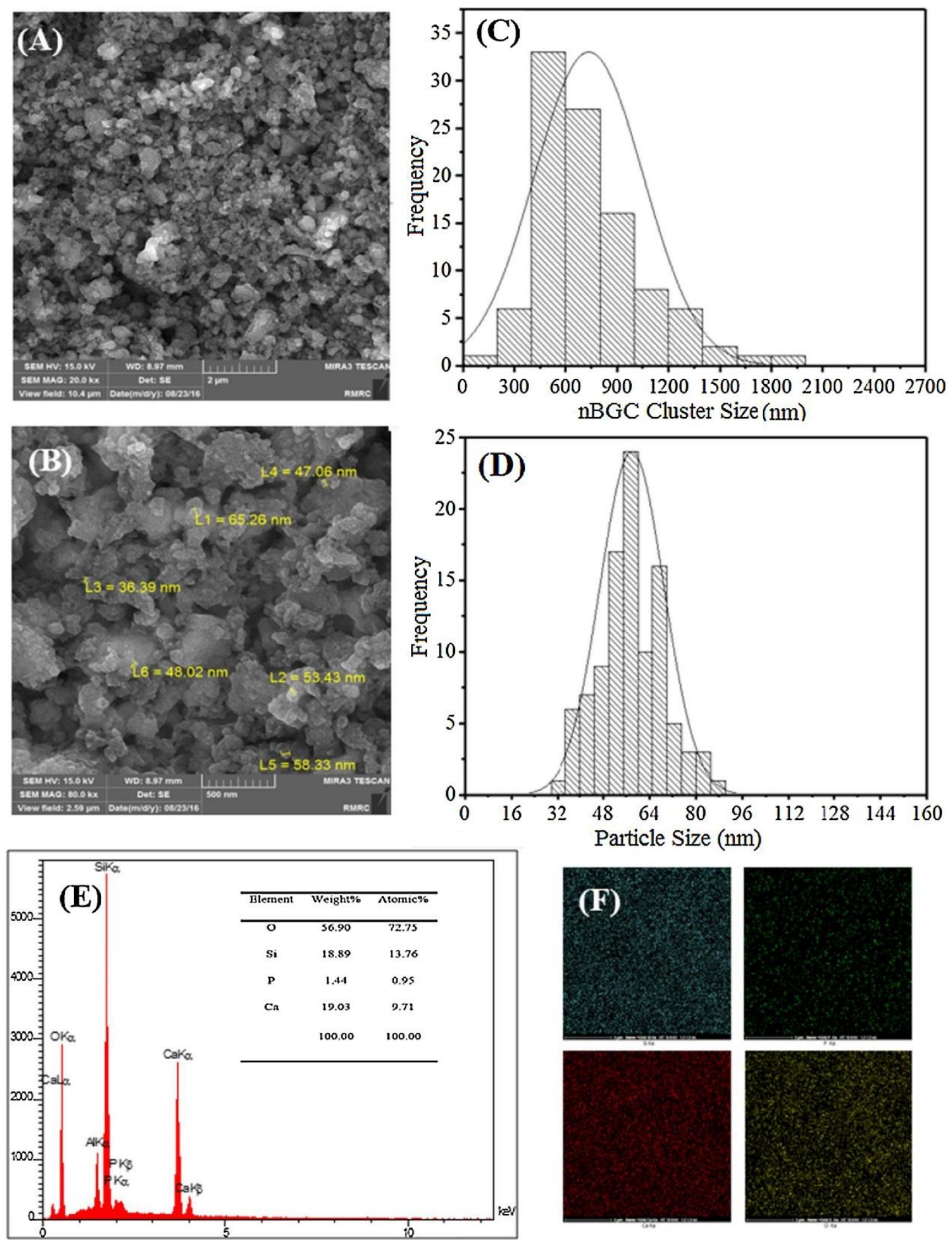

Fig. 3. FESEM image of $n B G C$ particles at two magnifications $(A, B)$, the histogram of $n B G C$ clusters and particles size distribution (C, D), EDX spectra (E), results of EDX analysis indicating $n B G C$ particles elements (Fig. E, inset) and mapping of $\mathrm{Si}, \mathrm{P}, \mathrm{Ca}$ and $\mathrm{O}$ elements in blue, green, red and yellow color, respectively (F). (For interpretation of the references to colour in this figure legend, the reader is referred to the web version of this article.)

SEM micrographs from cross sections of $\mathrm{CDH}$ and the composite scaffolds containing different $\mathrm{nBGC}$ content, such as 2, 8 and 16 (wt\%) (Fig. 4(A)), indicate macroporous nature of the scaffolds with homogenous pores. Freeze-drying is a technique to produce and control the porosity of hydrogels. The observed porous structure of the scaffolds can be attributed to free balk water in the composite structure which sublimates in the freeze-dryer and causes large pores. As illustrated in Figs. 4 and S2 
and summarized in Table S2, the addition of nBGC content resulted in increased pore size. The average pore size increased from 15.8 to 45,243 and $234 \mu \mathrm{m}$ for $\mathrm{CDH}$ to composite scaffolds containing 2, 8 and 16 (wt\%) of nBGC (Fig. 4(A)), respectively. While pore size is largely governed by freezing temperature, pore homogeneity is achieved by controlling freezing rate and providing a uniform contact surface (Angulo \& Sobral, 2016). The freeze-drying condition was same for all of the samples, then this factor cannot be responsible for increased porosity of the scaffolds. Such an increase in pore size relates to physicochemical properties of the hydrogels e.g., arise from increasing free water uptake with nBGC content, confirmed by swelling studies. Moreover, the addition of nBGC to CDH can effect on ECH performance as a chemical crosslinker, (Fig. 2(A $\left.A_{4}\right)$ ) which results in lower crosslinking of dextran chains, then reduces the mechanical strength. Therefore, freeze-drying of these composite scaffolds may cause larger pores. The increase of nBGC content from 2 to 16 (wt\%) can intensify this effect, then increase the average pore size. According to the obtained porosity and the sufficient pore size for tissue engineering scaffolds, which ranges 100-300 $\mu \mathrm{m}$ as reported earlier (Peter et al., 2009; Srinivasan, Jayasree, Chennazhi, Nair, \& Jayakumar, 2012), the prepared scaffolds are expected to have an appropriate function. It is worth to note, pores are necessary to bone tissue regeneration for the migration and proliferation of osteoblasts and mesenchymal cells, as well as vascularization. As shown, in comparison to apparently dense $\mathrm{CDH}$ pore walls with a smooth surface (Fig. $4(\mathrm{~A})$ inset), the pore walls of the composite scaffolds appear thicker, due to the embedded nBGC agglomerate. EDX spectra of CDH-nBGC scaffolds (Fig. 4(B)) confirm the incorporation of nanoparticles into dextran matrixes. It is worth to note that the characteristic peaks of gold $(\mathrm{Au})$, coated on samples and phosphorous $(\mathrm{P})$ probably overlapped in EDX spectra of $\mathrm{CDH}-8$ (wt\%) and $\mathrm{CDH}-16$ (wt\%) nBGC. Also, according to the mapping of Si element (Fig. 4(A) inset), particles were observed on the pore walls of the composite scaffold and uniformly dispersed in the matrix in low nBGC content ( 2 wt\%), but with some agglomerates in higher concentrations, such as 8 and 16 (wt\%). 

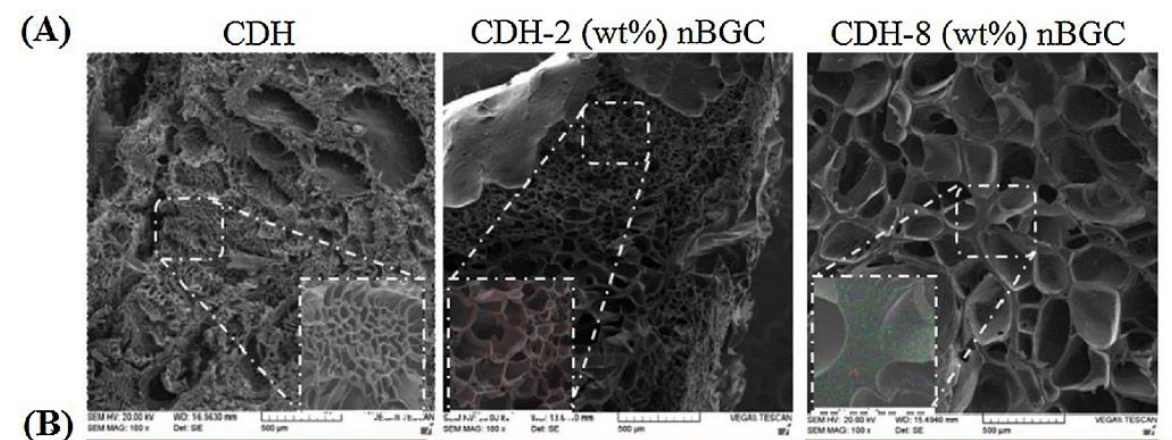

$\mathrm{CDH}-16(\mathrm{wt} \%) \mathrm{nBGC}$
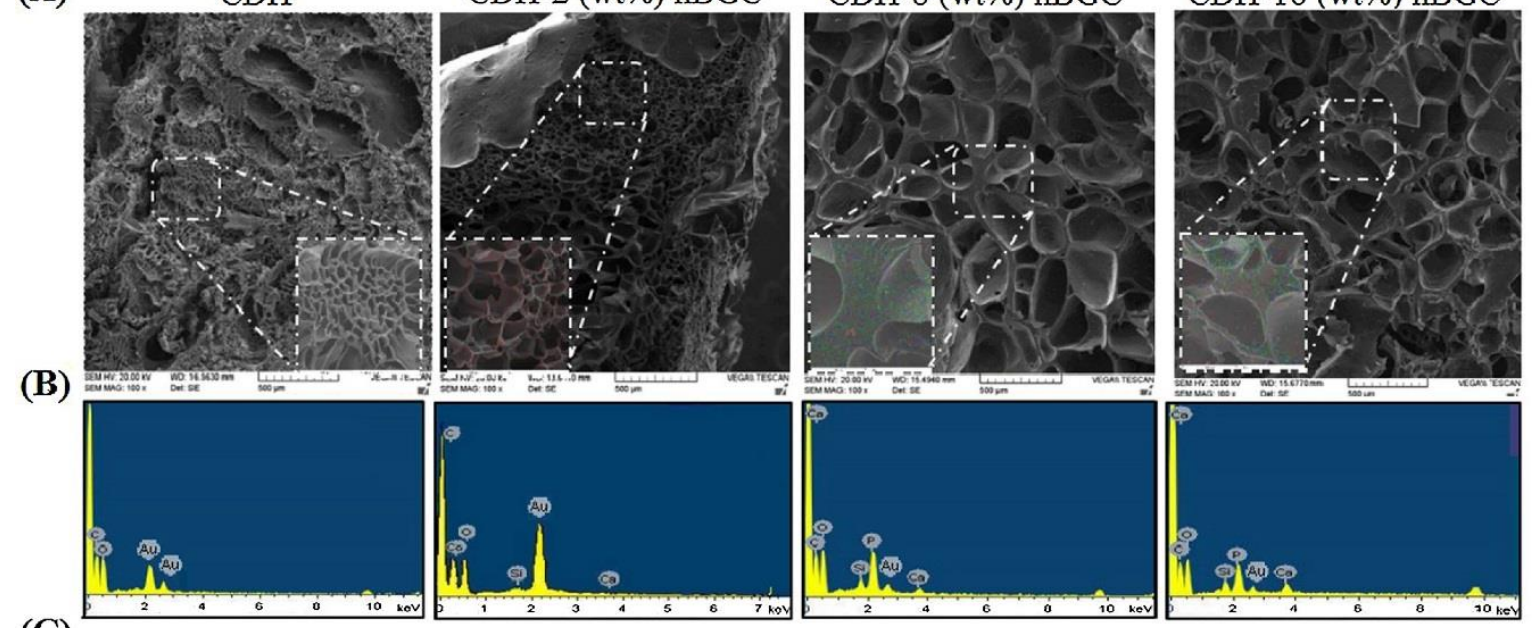

(C)
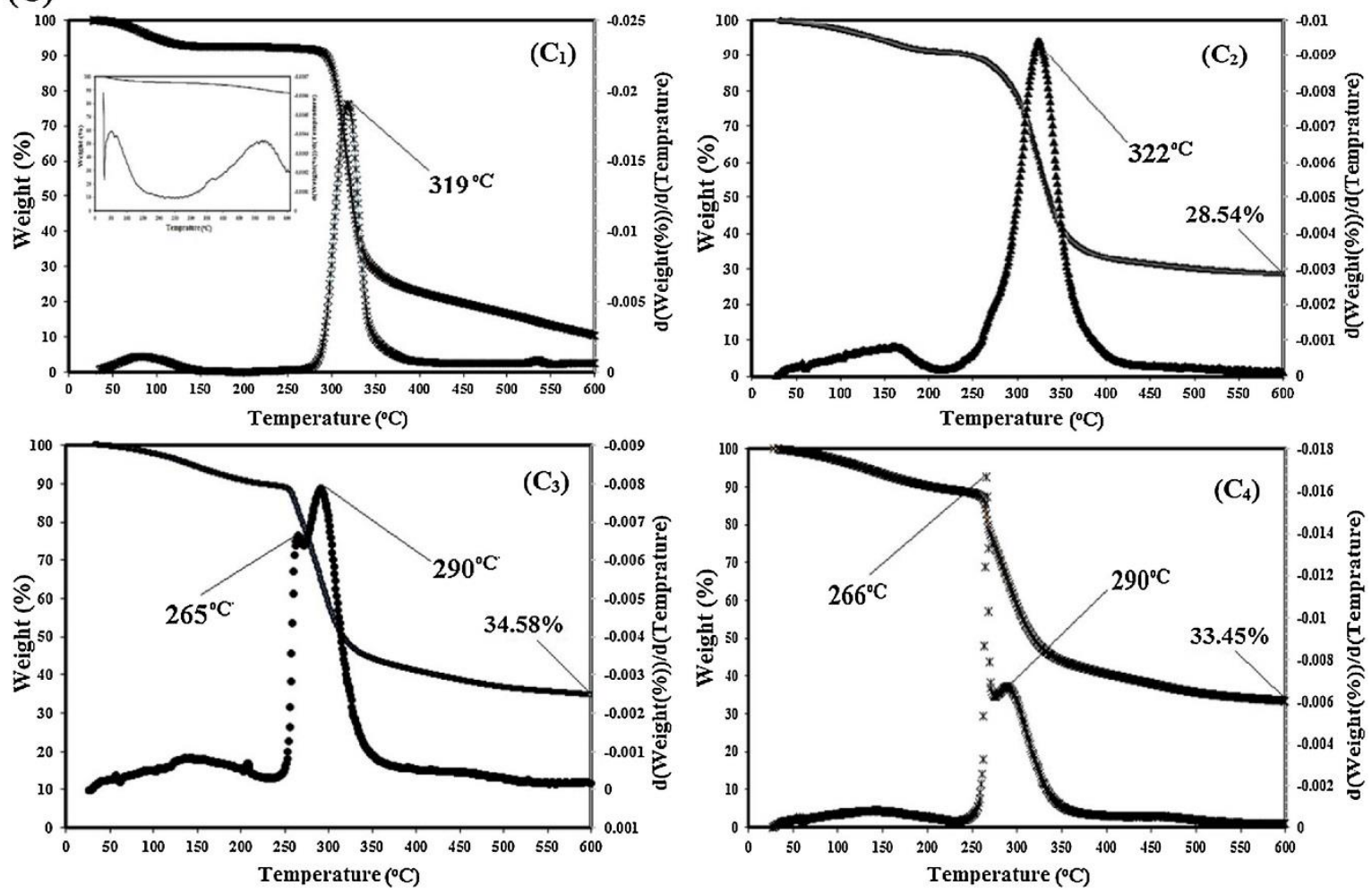

Fig. 4. SEM images of cross section of samples (A), EDX spectra and mapping of $\mathrm{Si}, \mathrm{P}, \mathrm{Ca}$ and $\mathrm{O}$ elements (B) of: $\mathrm{CDH}, \mathrm{CDH}-2$ (wt\%) nBGC, CDH-8 (wt\%) and CDH-16 (wt\%) scaffolds. TGA/DTG thermograms of virgin dextran $\left(\mathrm{C}_{1}\right), \mathrm{nBGC}$ (Inset), $\mathrm{CDH}\left(\mathrm{C}_{2}\right), \mathrm{CDH}-2$ (wt\%) nBGC $\left(\mathrm{C}_{3}\right)$ and $\mathrm{CDH}-8$ (wt\%) nBGC $\left(\mathrm{C}_{4}\right)$ nanocomposites.

\subsection{Thermal analysis}

The thermal behavior of virgin dextran, $\mathrm{CDH}$ and the $\mathrm{CDH}-\mathrm{nBGC}$ scaffolds containing various amounts of $\mathrm{nBGC}$ are examined with TGA/DTG, heated up to $600^{\circ} \mathrm{C}$, in order to identify the probable interactions occurring between dextran chains and $n B G C$ nanoparticles that leads to form the hybrid layers between two phases. (Fig. 4(C)). Table 1 provides details of the thermal behavior, based on the primary and derivative thermograms obtained for all samples. As the TGA curves show, no certain weight loss has been observed in nBGC nanoparticle between $50^{\circ} \mathrm{C}$ to $600^{\circ} \mathrm{C}$ (Fig. $4\left(\mathrm{C}_{1}\right)$ inset). 
Table 1. Results of Thermal Analysis Obtained for virgin dextran, CDH and CDH-nBGC composites.

\begin{tabular}{|c|c|c|c|c|c|}
\hline Samples & $\begin{array}{l}\text { Humidity } \\
\text { (w\%) at } \\
600^{\circ} \mathrm{C}\end{array}$ & $\begin{array}{c}\text { Onset of } \\
\text { thermal } \\
\text { degradation } \\
\left(C^{\circ}\right)\end{array}$ & $\begin{array}{l}\text { First Maximum } \\
\text { rate } \\
\text { decomposition } \\
\text { temperature }\left(C^{\circ}\right)\end{array}$ & $\begin{array}{c}\text { Second Maximum } \\
\text { rate } \\
\text { decomposition } \\
\text { temperature }\left({ }^{\circ} \mathrm{C}\right)\end{array}$ & $\begin{array}{l}\text { Final of thermal } \\
\text { decomposition } \\
\text { temperature }\left({ }^{\circ} \mathrm{C}\right)\end{array}$ \\
\hline $\begin{array}{l}\text { virgin } \\
\text { dextran }\end{array}$ & 7.95 & 258.96 & - & 319 & 402.12 \\
\hline $\mathrm{CDH}$ & 8.67 & 238 & - & 322 & 400 \\
\hline $\begin{array}{c}\text { CDH- } \\
\text { 2(wt\%) } \\
\text { nBGC }\end{array}$ & 9.15 & 250 & 265 & 290 & 380 \\
\hline $\begin{array}{l}\text { CDH- } \\
8(w t \%) \\
\text { nBGC }\end{array}$ & 9.66 & 245 & 266 & 290 & 365 \\
\hline
\end{tabular}

For each material (virgin dextran, $\mathrm{CDH}$, and the nanocomposite scaffolds), the TGA graph can be divided into three main thermal regions (Fig. $4\left(C_{2}-C_{4}\right)$ ). The first region ranged from room temperature to $200{ }^{\circ} \mathrm{C}$, with all samples undergoing some weight loss, due to loss of moisture content as hydrogenbonded water molecules from the glucosides moieties of scaffolds (Hou et al., 2006). This occurrence could possibly be due to the elimination of the residual $\mathrm{ECH}$ used in the preparation of $\mathrm{CDH}$. The second region ranged from 238 to $322^{\circ} \mathrm{C}$, where the main decomposition occurred, which can be attributed to the polysaccharide structure of dextran and crosslinking bonds. As shown in Fig. 4(C), virgin dextran and $\mathrm{CDH}$ behave differently than composite scaffolds. The onset of thermal degradation is lower for both $\mathrm{CDH}\left(238^{\circ} \mathrm{C}\right)$ and $\mathrm{CDH}-\mathrm{nBGC}$ composites $\left(250^{\circ} \mathrm{C}\right.$ and $245^{\circ} \mathrm{C}$ for $\mathrm{CDH}-2$ (wt\%) and CDH8 (wt\%) nBGC, respectively) in comparison to virgin dextran $\left(258.96^{\circ} \mathrm{C}\right)$. Weight loss rate for virgin dextran, within a certain range of temperature, is increased rapidly, in contrast to what is observed for $\mathrm{CDH}$. This weight loss may be attributed to the different bond strength between the crosslinked backbones (i.e. dextran chains connected via ether bonds due to the chemical crosslinking reaction with $\mathrm{ECH}$ and intrabackbone covalent bonds) and interaction between dextran-nBGC functional groups (Ibănescu, May, \& Allan, 2008). The presence of nBGC has another major effect. According to DTG diagrams in Fig. $4\left(C_{3}\right)$ and $4\left(C_{4}\right)$, the nBGC particles caused two peaks in the second region of thermal destruction. The new peak is in the range of $250-265^{\circ} \mathrm{C}$ and $245-266^{\circ} \mathrm{C}$ for $\mathrm{CDH}-2$ (wt\%) nBGC and $\mathrm{CDH}-8$ (wt\%) nBGC, respectively, with its intensity, increased by the addition of nBGC content. These results can be attributed to local hotspots created by the nanoparticle agglomeration.

An increase in thermal stability of the CDH was observed in comparison to the virgin dextran, which is certainly due to its crosslinking and consequent improvement in thermal stability. The third region is generally from 360 to $600{ }^{\circ} \mathrm{C}$, with approximately no significant weight loss. Lastly, these curves confirm that the residuals could be removed before $600^{\circ} \mathrm{C}$, making this the appropriate temperature for a full stabilization of the structure.

It is worth to note that the residual weight was calculated for $\mathrm{CDH}, \mathrm{CDH}-2$ (wt\%) nBGC and CDH-8 (wt\%) nBGC composite scaffolds according to TGA curves, which were equal to $28.54 \%, 34.58 \%$ and $33.45 \%$ respectively, shown on Fig. $4(\mathrm{C})$. The observed difference in residual weight between $\mathrm{CDH}$ and $\mathrm{CDH}-2$ (wt\%) nBGC composite scaffolds confirms the presence of nBGC particles. However, $\mathrm{CDH}-2$ (wt\%) nBGC and CDH-8 (wt\%) nBGC composite scaffolds, have almost the equal residual weight. 
Therefore, it seems that the most covalent bonds in dextran structure degrade by heating the composite samples up to $600 \mathrm{oC}$, but the complete degradation of polymeric matrix does not happen.

\subsection{Swelling studies}

The swelling behavior of $\mathrm{CDH}$ and nanocomposite hydrogels is presented in Fig. 5(A, B). It was found that $\mathrm{CDH}$ has the highest value of ESR (1272\%) compared to all other samples. The addition of 2 (wt\%) $\mathrm{nBGC}$ particles to $\mathrm{CDH}$ led to a decrease in ESR (764.7\%). The reduction in ESR can be attributed to the physical interaction between dextran-nBGC. The released $\mathrm{Ca}^{2+}$ ions of silica structure in $\mathrm{nBGC}$ may have a role as a physical crosslinker, causing interaction between hydroxyl groups of two dextran chains. Similar swelling results were observed by Peter et al. (Peter, Binulal, Soumya et al., 2010) and Gantar et al. (Gantar et al., 2014). By increasing the nBGC percentage from 2 to 16 (wt\%), the ESR increased to $1276.4 \%$, which is approximately equal to the pure hydrogel swelling ratio. Such an increase can be due to osmotic pressure, which increases with water absorption (Livney et al., 2001). Nanoparticles agglomeration in higher percentages followed by decreasing in Dex-nBGC interface can lead to decreased physical interactions between Dex-nBGC. Consequently, a weaker hydrogel network form that is capable of more water uptake. The probable effect of $\mathrm{nBGC}$ on the ECH performance as a chemical crosslinker is an increase water uptake, as seen in Fig. 2( $\left.A_{4}\right)$. Additionally, with respect to SEM results (seen in Fig. 4(A)), increasing scaffold pore size at higher nBGC concentrations can cause entrapment of more water molecules in scaffold pores, causing an increase in ESR. Maquet et al. showed that the addition of $\mathrm{nBGC}$ particles to a polymer increased water absorption (Maquet, Boccaccini, Pravata, Notingher, \& Jérôme, 2004). Swelling by increasing the pore size and porosity can aid in supplying nutrients and oxygen to the interior regions of the composite scaffolds.
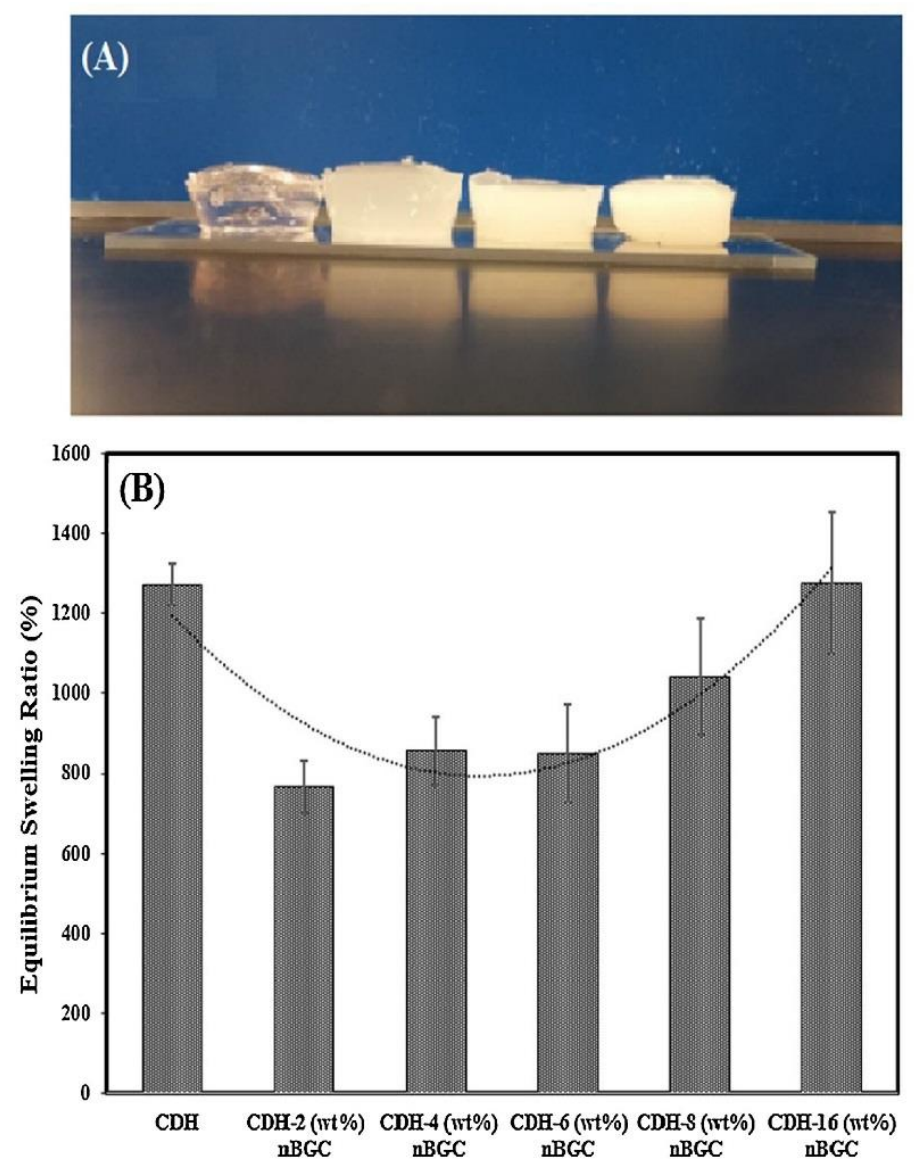
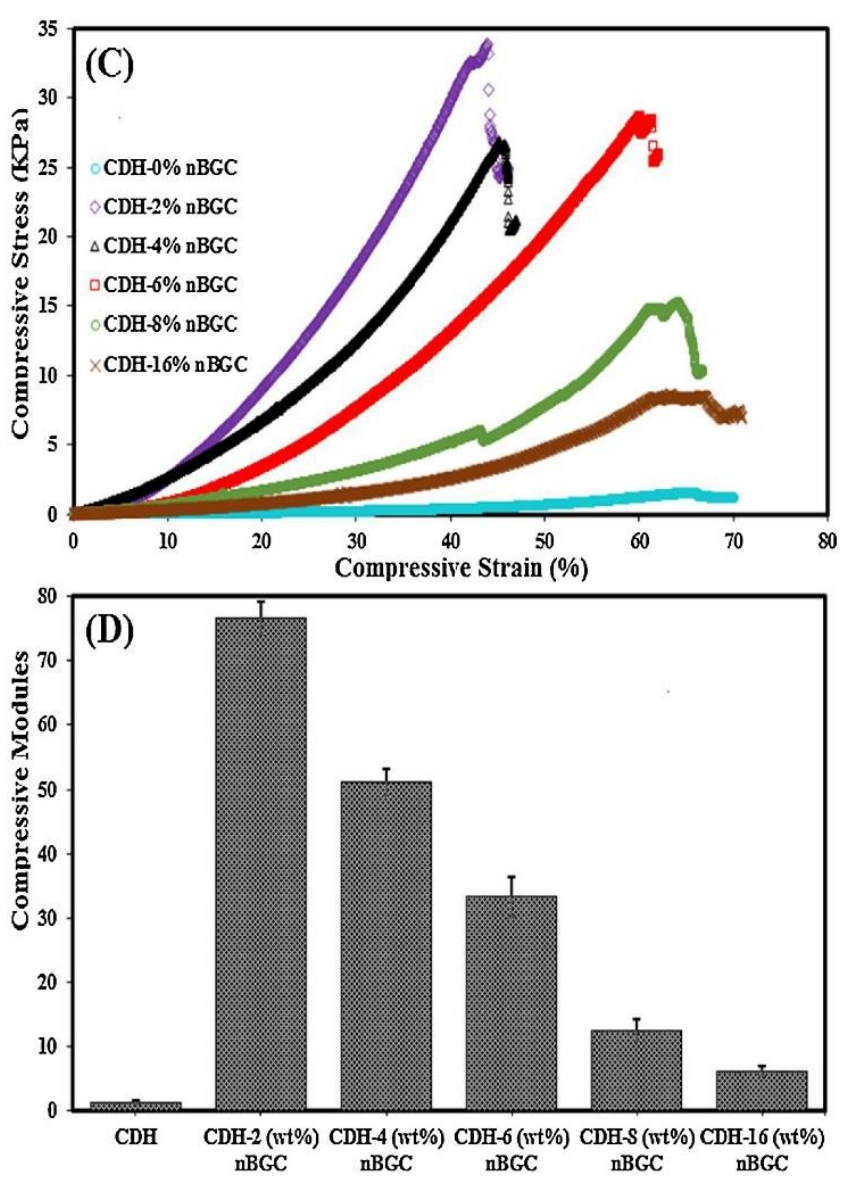
Fig. 5. Visual aspect of the samples at swollen state (A), Swelling behavior of the Dex composite hydrogels with various $n B G C$ content (B), Stress-Strain curves of nanocomposite scaffolds (C) and Compressive modulus of various nanocomposite scaffolds (D).

\subsection{Mechanical test}

Generally, an ideal tissue engineering scaffold should be biocompatible and porous with sufficient mechanical properties. The swollen nanocomposite scaffolds were tested to determine the effects of using $\mathrm{nBGC}$ as a mineral component on the mechanical properties of the hydrogels. Stress-strain graph and comparison of the compressive modulus of the nanocomposite scaffolds, including $\mathrm{CDH}$ and $\mathrm{CDH}$ nBGC scaffolds, are portrayed in Fig. 5(C, D). According to Fig. 5(C), all samples show non-linear stressstrain changes. Swollen $\mathrm{CDH}$ scaffold in the presence of nBGC particles first results in compressive stress at failure point and increased compressive modulus, followed by a downward trend. Compressive stress at failure point and modulus in $\mathrm{CDH}$ were equal to $1.5 \mathrm{kPa}$ and $1.3 \mathrm{kPa}$, respectively. Addition of 2 (wt\%) nBGC to CDH enhanced stress at failure point and compressive modulus, to $33.42 \mathrm{kPa}$ and $76.61 \mathrm{kPa}$, respectively. It is worth to note that many factors can contribute to the observed mechanical response of the inorganic/organic composites, such as particle shape, particle size, particle size distribution of the inorganic component and the interfacial interactions between the inorganic and organic components (Cai et al., 2009). Such an increase in compressive stress and modulus can also be attributed to the homogenous distribution of nanoparticles then proper polymer/nBGC interface (according to Fig. 2( $\left.\mathrm{A}_{3}\right)$ (as a mineral and improving phase. The SEM and EDX results in Fig. 4 confirms this homogenous distribution. Also, the interaction between dextran and $\mathrm{Ca}^{2+}$ ions, which plays a physical crosslinker role shown in Fig. 2( $\left.\mathrm{A}_{2}\right)$, increases crosslinking degree and enhances mechanical properties. Higher nBGC content from 4 to 16 (wt\%) resulted in a reduction of stress and modulus. The uncontrolled nanoparticle agglomeration then, the lower interface between polymer and ceramic at the higher nBGC content (confirmed by SEM and EDX results in Fig. 4) reduces the effect of $n B G C$ particles as an active filler (described in Fig. $2\left(A_{3}\right)$ ) then resulted in weaker mechanical properties. Moreover, the creation of larger pores on polymer/ceramic interface as observed in SEM micrographs could be responsible for the reduction of mechanical properties. Finally, the probable effect of $\mathrm{nBGC}$ on $\mathrm{ECH}$ function (Fig. 2( $\left.\mathrm{A}_{4}\right)$ ) by reducing the crosslinking and also increasing swelling ratio at higher $n B G C$ content, weaken the composite scaffolds. Although the reinforcement of $\mathrm{CDH}$ scaffolds with $\mathrm{nBGC}$ particles has contributed to improve the mechanical properties, the prepared composite scaffolds have obviously shown lower compressive modulus compared to desired value for the natural bone (Azami, Moztarzadeh, \& Tahriri, 2010; Johnson \& Herschler, 2011). Then, the prepared scaffolds can be qualified for non-load-bearing applications such as some treatments of oral and maxillofacial defects (Basha \& Doble, 2015). A further improvement of the mechanical properties is proposed by improved processing, mainly a better dispersion of the $n B G C$ particles in the $\mathrm{CDH}$ matrix.

As a summarized structural investigation, the addition of nBGC content from 2 to 16 (wt\%) has decreased mechanical properties while increased the equilibrium swelling ratio of CDH scaffolds. The observed water uptake of the scaffolds can indicate to the pores size of the scaffolds which are critical for the migration and proliferation of osteoblasts and mesenchymal cells. Due to the sufficient pore size for tissue engineering scaffolds, ranges 100-300 $\mu \mathrm{m}$ as reported by Peter et al. (Peter et al., 2009; Srinivasan et al., 2012), the composite scaffolds containing 2, 8 and 16 (wt\%) nBGC with better water uptake and larger pores, also confirmed with SEM micrographs in Fig. 4 were selected for biomineralization and biological characterizations. 


\subsection{Evaluation of in vitro mineralization}

Submersion in SBF is a standard indicator of in vitro reactivity, providing an indication of the speed with which apatite nucleation and growth occurs. In order to investigate the effect of nBGC content on the ability of composites to induce HA formation and the bioactivity of the samples, composite scaffolds containing 2, 8 and 16 (wt\%) nBGC were immersed in the SBF solution for 28 days. The surface morphology of the CDH-nBGC scaffolds containing various $\mathrm{nBGC}$ content before and after soaking in SBF are depicted in Fig. 6 . The sublimated water gets out in vapor form from hydrogel surface lead to roughness of surface for some samples before soaking in the SBF. After the immersion of the composite scaffolds containing 2 (wt\%) nBGC in the SBF, no change in morphology is observed within 28 days, due to the low content of $n B G C$, whereas the increase of $n B G C$ content to 8 (wt\%) leads to an increase in surface roughness, indicating the formation of HA crystals (Fig. 6(A)). At higher magnification (Fig. 6(C)), cauliflower-like HA crystals formed on the surface of CDH-8 (wt\%) nBGC scaffold, in which each particle comprised of many entangled rod-shaped crystals. Size distribution of HA rod-shaped crystals can be seen in the corresponding histogram (Fig. 6(D)), indicating the size range of HA crystals, mainly between 471 and $2479 \mathrm{~nm}$. Gantar et al. (Gantar et al., 2014) and Mota et al. (Mota et al., 2012), also report a similar morphology. The morphology of crystals tends to change as $\mathrm{nBGC}$ content is increased from 8 to 16 (wt\%). The observed wrinkled surface for CDH-16 (wt\%) nBGC composite with the approximate smoothness can be attributed to the dissolution of the rod-shaped crystals in SBF. During the soaking process, dissolution and precipitation of calcium phosphate crystals and formation of apatite layer took place continually. Biodegradation of polymeric scaffold may be responsible for uniformity and smoothness of the surface. 

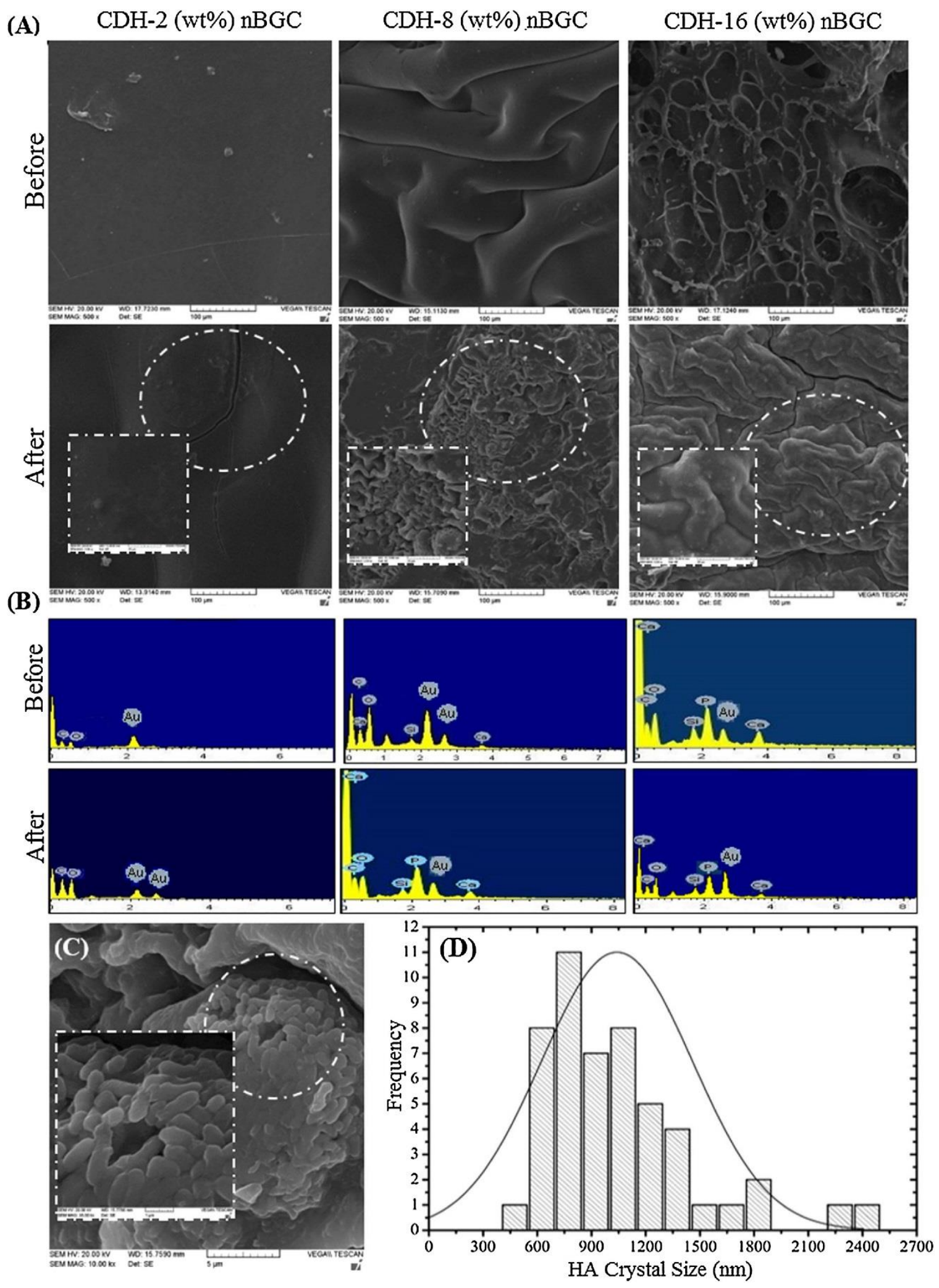

Fig. 6. SEM images of the outer surface of samples (A), EDX spectra of Si, P, Ca and O elements of: CDH-2 (wt\%) nBGC, CDH-8 (wt\%), CDH-16 (wt\%) composite scaffolds before and after 28 days immersion in SBF (B), Cauliflower-like HA clusters formation on the surface of $\mathrm{CDH}-8$ (wt\%) nBGC (C) and corresponding histogram of HA crystals size distribution (D). 
The EDX data of composite scaffolds both before and after immersion in SBF is presented in Fig. 6(B) and Table S.2. After 28 days immersion in SBF, no calcium ( $\mathrm{Ca}$ ) or phosphorous (P) was detected on the surface of CDH-2 (wt\%) nBGC scaffolds (Fig. 6(B)), confirming SEM micrographs (Fig. 6(A)) for no formation of HA crystals. By increasing the nBGC content to 8 and 16 (wt\%), the silicon (Si) content of these composite scaffolds decreased, followed by an increase in $\mathrm{Ca}$ and $\mathrm{P}$ content compared to the previous immersion of scaffolds. The increases in $\mathrm{Ca}$ and $\mathrm{P}$, accompanied by a decrease in the concentration of $\mathrm{Si}$, can support the indications of the development of apatite in CDH-nBGC scaffolds, observed in Fig. 6(A). Moreover, for $\mathrm{CDH}-8$ (wt\%) nBGC, Ca/P ratio of 1.98 (weight ratio) and 1.54

(molar ratio) were confirmed by EDX analysis, which is approximately close to the normal $\mathrm{Ca} / \mathrm{P}$ ratio of 1.67 (for biological apatite), representing the formation of biologic HA. FTIR and XRD results in Fig. S3 also confirmed the HA formation.

\subsection{Cellular characterizations}

The fluorescent images of $\mathrm{HOB}$ cells on the $\mathrm{CDH}$ and composite scaffolds have been demonstrated in Fig. 7(A), which shows the adhered cells on CDH-8 (wt\%) nBGC and CDH-16 (wt\%) nBGC are greater than $\mathrm{CDH}$ and $\mathrm{CDH}-2$ (wt\%) nBGC. Also seen in Fig. 7(A), the cells showed poor adhesion on the pristine $\mathrm{CDH}$, where a small number of rounded and clumped cells were observed. An increased number of HOB were seeded on the $\mathrm{CDH}-8$ (wt\%) nBGC and $\mathrm{CDH}-16$ (wt\%) nBGC composite scaffolds. The cells were observed to attach to the $\mathrm{CDH}-2$ (wt\%) nBGC, still rounded in shape and proliferated in clumps, suggesting loose adhesion of the cells. The incorporation of 8 (wt\%) nBGC and 16 (wt\%) nBGC significantly increased the number of cells adhered to $\mathrm{CDH}$ composite scaffolds. Moreover, the cells had a more stretched morphology and spread on $\mathrm{CDH}-8$ (wt\%) nBGC and $\mathrm{CDH}-16$ (wt\%) nBGC composite scaffolds. 
(A)
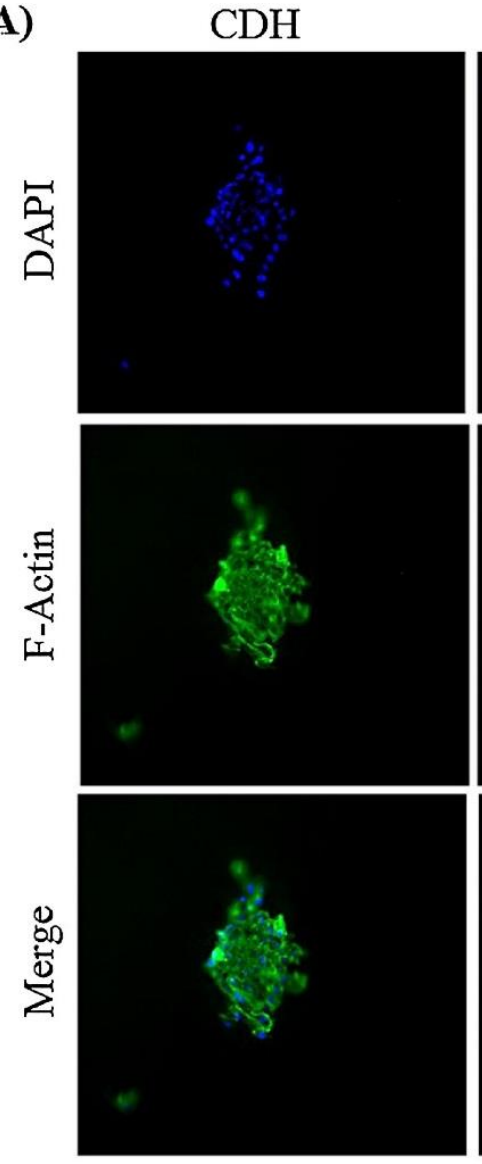

(B)

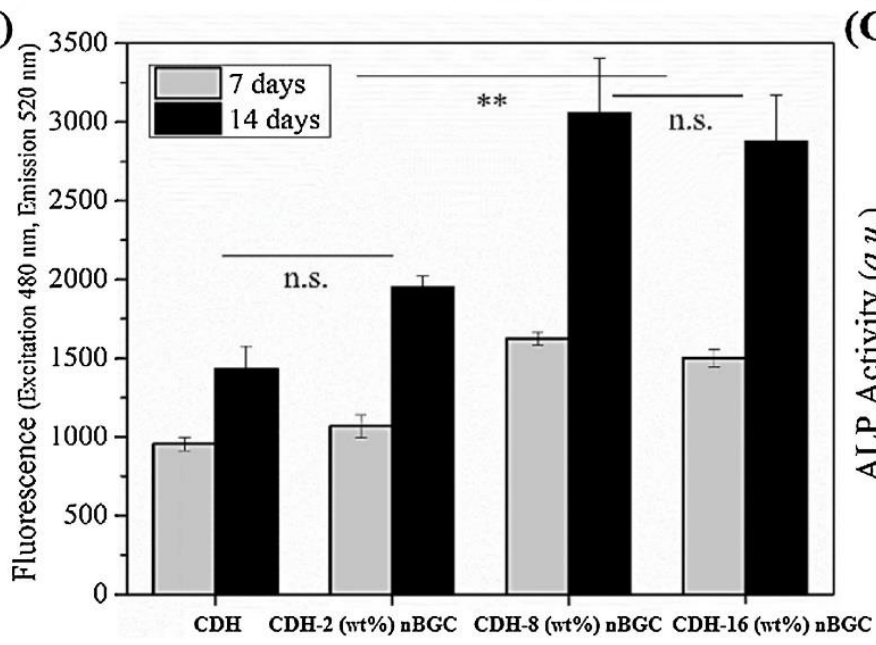

$\mathrm{CDH}-2(\mathrm{wt} \%) \mathrm{nBGC}$
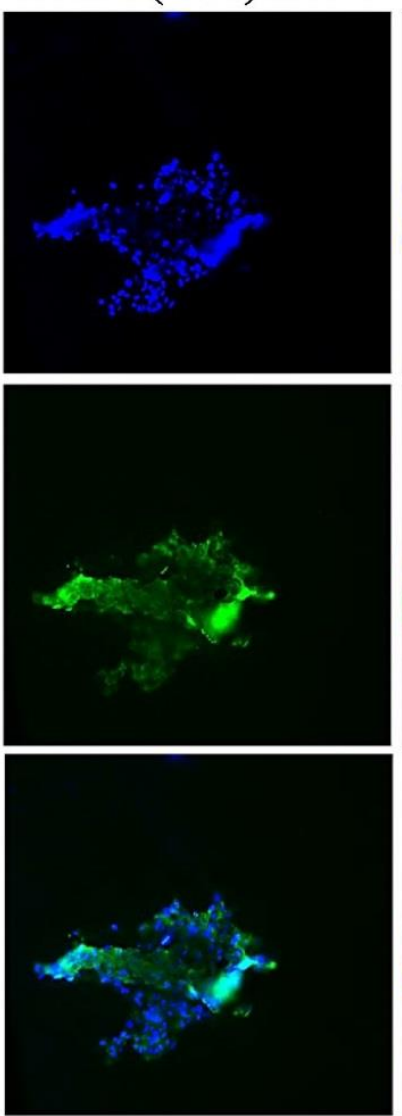
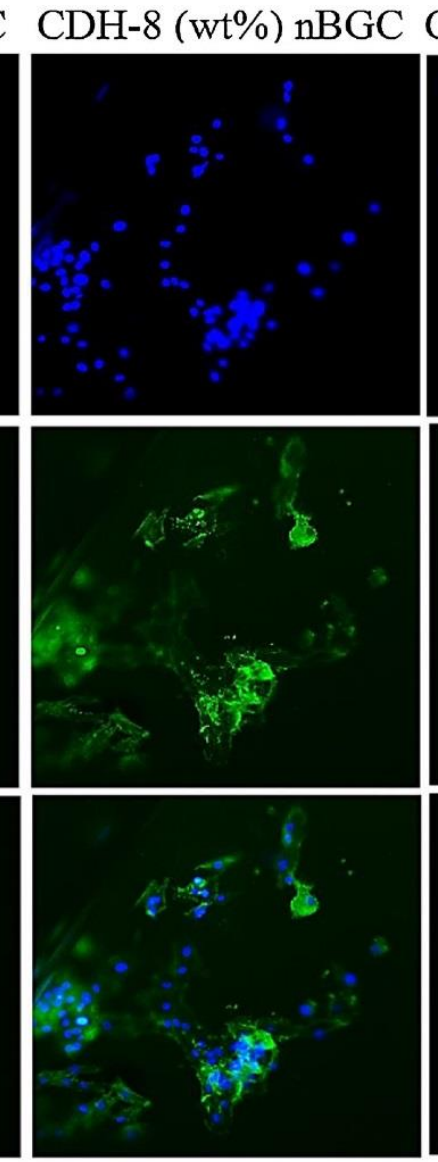

$\mathrm{CDH}-16(\mathrm{wt} \%) \mathrm{nBGC}$
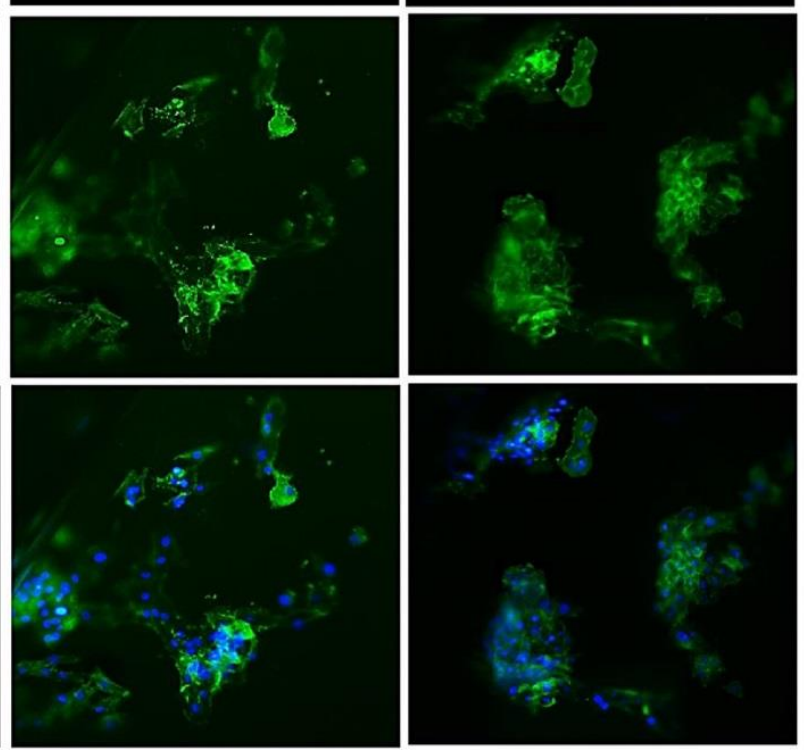

(C)

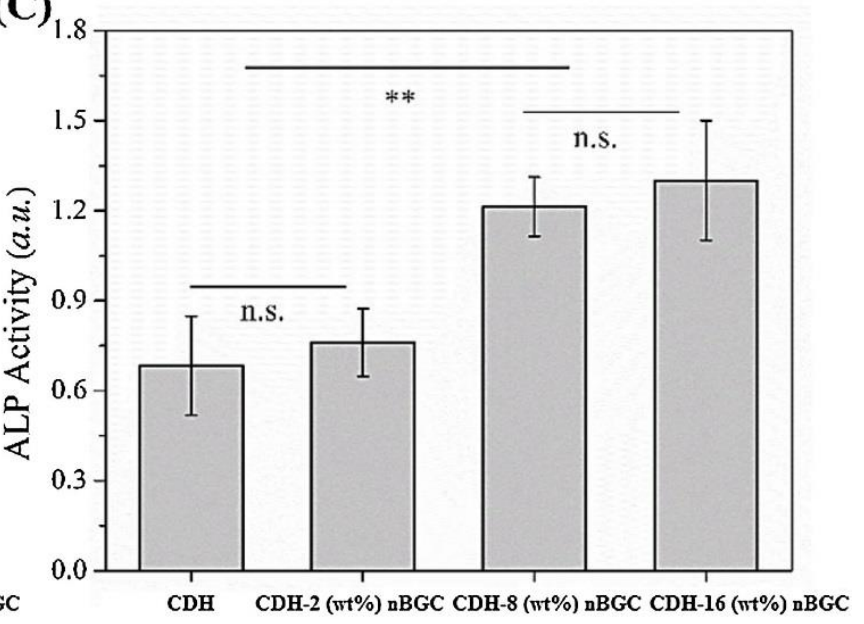

Fig. 7. (A) Immunofluorescence images of cultured $\mathrm{HOB}$ cells on $\mathrm{CDH}$ and composite scaffolds, (B) the PrestoBlue viability of $\mathrm{HOB}$ cells on hydrogels over two weeks and (C) Alkaline phosphatase (ALP) activity of HOB cells at day 14.

The cell proliferation and Alkaline Phosphatase (APase) activity, as a marker of HOB functions, were studied over two weeks. The cell viability of $\mathrm{HOB}$ cultured on the $\mathrm{CDH}$ and composite scaffolds containing 2, 8 and 16 (wt\%) nBGC over two weeks has been compared in Fig. 7(B). The results show that the number of HOB cells significantly increased from 7 th day to 14 th day in all groups $(P<0.05)$. It was found that the composite scaffolds containing 8 and 16 (wt\%) nBGC offer drastically improved cell viability compared to the $\mathrm{CDH}$ and composite scaffolds containing 2 (wt\%) nBGC, after 7 and 14 days. 
Notice that no significant difference was observed between $\mathrm{CDH}$ and $\mathrm{CDH}-2$ (wt\%) nBGC, as well as between $\mathrm{CDH}-8$ (wt\%) nBGC and $\mathrm{CDH}-16$ (wt\%) nBGC. $(\mathrm{P}<0.05)$.

The results of alkaline phosphatase (ALP) assay on the 14th day was shown in Fig. 7(C). The ALP activity of $\mathrm{HOB}$ cells cultured on $\mathrm{CDH}-8$ (wt\%) nBGC and $\mathrm{CDH}-16$ (wt\%) nBGC was found to be significantly higher than other groups. Such an improvement could be associated with the incorporation of the appropriate amount of $\mathrm{nBGC}$ phase into the dextran matrix, enhancing cell adhesion, spreading and function.

In accordance with our results, it has been reported that $\mathrm{SiO}_{2}$ improves the reactivity of surface to interaction with body fluids and produces active sites for mineral precipitation in vitro/vivo. $\mathrm{CaP}-\mathrm{SiO}_{2}$ constructs were reported to encourage osteoblasts through differentiation stage by upregulating osteopontin and osteocalcin mRNA expression. Such effects are likely due to gradual scaffold dissolution and release of $\mathrm{Si}^{4+}$ ions into the culture medium, which plays an important role in cellular response (Tousi et al., 2013). In another study, it has been reported that Si ions improve osteoblastic cell proliferation and enhance collagen synthesis (Li, Wei, Sun, \& Guan, 2013).

\section{Conclusion}

This work presents bioactive glass ceramic reinforced CDHs (CDH-nBGC) as novel materials proposed for scaffolding in bone-tissue engineering. Despite the sphere nBGC particles becoming agglomerated within the dextran matrix at higher concentrations and causing an unfavorable effect on thermal stability, they contributed significantly to an improved microstructure and mechanical properties of the original $\mathrm{CDH}$. The scaffolds were macroporous with pores in the range of $15.8-243.1 \mu \mathrm{m}$ and nanoparticles dispersed on pore walls. The addition of $n B G C$ resulted in the reduction of swelling ratio at first, followed by an increase. XRD and FT-IR analysis confirmed the presence of nanoparticles. Bioactivity studies showed that the prepared composite scaffolds were bioactive. Initial biological testing conclusively showed that the composite scaffolds were able to support HOB growth and maintenance of their osteogenic phenotype without compromising its viability, thus indicating its potential for use in bone augmentation and clinical applications. The presented CDH-nBGC scaffolds show great promise for applications in bone regeneration, both for acellular or cellular strategies.

\section{Acknowledgment}

The authors are grateful to Iran National Science Foundation (INSF) Grant No. 93043263, for their kind financial support on the research.

\section{Appendix A. Supplementary data}

The following is Supplementary data to this article: Download Acrobat PDF file (1MB) 


\section{References}

Al-Oweini and El-Rassy, 2009 R. Al-Oweini, H. El-Rassy. Synthesis and characterization by FTIR spectroscopy of silica aerogels prepared using several $\mathrm{Si}(\mathrm{OR})_{4}$ and $\mathrm{R}^{\prime \prime} \mathrm{Si}(\mathrm{OR})_{3}$ precursors. Journal of Molecular Structure, 919 (1) (2009), pp. 140-145.

Angulo and Sobral, 2016 D.E.L. Angulo, P.J.d.A. Sobral. The effect of processing parameters and solid concentration on the microstructure and pore architecture of gelatin-chitosan scaffolds produced by freeze-drying. Materials Research, 19 (4) (2016), pp. 839-845.

Azami et al., 2010 M. Azami, F. Moztarzadeh, M. Tahriri. Preparation, characterization and mechanical properties of controlled porous gelatin/hydroxyapatite nanocomposite through layer solvent casting combined with freeze-drying and lamination techniques. Journal of Porous Materials, 17 (3) (2010), pp. 313-320.

Basha and Doble, 2015 R.Y. Basha, M. Doble. Design of biocomposite materials for bone tissue regeneration. Materials Science and Engineering: C, 57 (2015), pp. 452-463.

Blaker et al., 2005 J.J. Blaker, V. Maquet, A.R. Boccaccini, R. Jérôme, A. Bismarck. Wetting of bioactive glass surfaces by poly ( $\alpha$-hydroxyacid) melts: Interaction between bioglass ${ }^{\oplus}$ and biodegradable polymers. E-Polymers, 5 (1) (2005), pp. 248-260.

Coates, 2000 J. Coates. Interpretation of infrared spectra, a practical approach. Encyclopedia of Analytical Chemistry (2000), pp. 10815-10837.

Deepthi et al., 2016 S. Deepthi, J. Venkatesan, S.-K. Kim, J.D. Bumgardner, R. Jayakumar. An overview of chitin or chitosan/nano ceramic composite scaffolds for bone tissue engineering. International Journal of Biological Macromolecules, 93 (2016), pp. 1338-1353.

Deux et al., 2002 J.-F. Deux, S. Prigent-Richard, G. d'Angelo, L.J. Feldman, E. Puvion, D. LogeartAvramoglou, et al. A chemically modified dextran inhibits smooth muscle cell growth in vitro and intimal in stent hyperplasia in vivo. Journal of Vascular Surgery, 35 (5) (2002), pp. 973-981.

Dhandayuthapani et al., 2011 B. Dhandayuthapani, Y. Yoshida, T. Maekawa, D.S. Kumar. Polymeric scaffolds in tissue engineering application: A review. International Journal of Polymer Science (2011), p. 2011.

Drury and Mooney, 2003 J.L. Drury, D.J. Mooney. Hydrogels for tissue engineering: Scaffold design variables and applications. Biomaterials, 24 (24) (2003), pp. 4337-4351.

El-Fiqi et al., 2013 A. El-Fiqi, J.H. Lee, E.-J. Lee, H.-W. Kim. Collagen hydrogels incorporated with surface-aminated mesoporous nanobioactive glass: Improvement of physicochemical stability and mechanical properties is effective for hard tissue engineering. Acta Biomaterialia, 9 (12) (2013), pp. 9508-9521.

Filgueiras et al., 1993 M.R. Filgueiras, G. La Torre, L.L. Hench. Solution effects on the surface reactions of a bioactive glass. Journal of Biomedical Materials Research Part A, 27 (4) (1993), pp. 445-453.

Fricain et al., 2013 J.C. Fricain, S. Schlaubitz, C. Le Visage, I. Arnault, S.M. Derkaoui, R. Siadous, et al. A nano-hydroxyapatite-pullulan/dextran polysaccharide composite macroporous material for bone tissue engineering. Biomaterials, 34 (12) (2013), pp. 2947-2959.

Gantar et al., 2014 A. Gantar, L.P. da Silva, J.M. Oliveira, A.P. Marques, V.M. Correlo, S. Novak, et al. Nanoparticulate bioactive-glass-reinforced gellan-gum hydrogels for bone-tissue engineering. Materials Science and Engineering: C, 43 (2014), pp. 27-36.

Heinze et al., 2006 T. Heinze, T. Liebert, B. Heublein, S. Hornig. Functional polymers based on dextran. Polysaccharides II, Springer (2006), pp. 199-291.

Hench, 1991 L.L. Hench. Bioceramics: From concept to clinic. Journal of the American Ceramic Society, 74 (7) (1991), pp. 1487-1510. 
Hoffman, 2012 A.S. Hoffman. Hydrogels for biomedical applications. Advanced Drug Delivery Reviews, 64 (2012), pp. 18-23.

Horner et al., 2010 E.A. Horner, J. Kirkham, D. Wood, S. Curran, M. Smith, B. Thomson, et al. Long bone defect models for tissue engineering applications: Criteria for choice. Tissue Engineering Part B: Reviews, 16 (2) (2010), pp. 263-271.

Hou et al., 2006 X. Hou, J. Yang, J. Tang, X. Chen, X. Wang, K. Yao. Preparation and characterization of crosslinked polysucrose microspheres. Reactive and Functional Polymers, 66 (12) (2006), pp. 1711-1717.

Ibănescu et al., 2008 B.C. Ibănescu, O. May, M. Allan. Cleavage of the ether bond by electron impact: Differences between linear ethers and tetrahydrofuran. Physical Chemistry Chemical Physics, 10 (11) (2008), pp. 1507-1511.

Imren et al., 2006 D. Imren, M. Gümüşderelioğlu, A. Güner. Synthesis and characterization of dextran hydrogels prepared with chlor-and nitrogen-containing crosslinkers. Journal of Applied Polymer Science, 102 (5) (2006), pp. 4213-4221.

Jazayeri et al., 2017 H.E. Jazayeri, M. Tahriri, M. Razavi, K. Khoshroo, F. Fahimipour, E. Dashtimoghadam, et al. A current overview of materials and strategies for potential use in maxillofacial tissue regeneration. Materials Science and Engineering: C, 70 (2017), pp. 913-929.

Johnson and Herschler, 2011 A.J.W. Johnson, B.A. Herschler. A review of the mechanical behavior of $\mathrm{CaP}$ and $\mathrm{CaP} /$ polymer composites for applications in bone replacement and repair. Acta Biomaterialia, 7 (1) (2011), pp. 16-30.

Jonker et al., 2012 A.M. Jonker, D.W. Löwik, J.C. van Hest. Peptide-and protein-based hydrogels. Chemistry of Materials, 24 (5) (2012), pp. 759-773.

Kargozar et al., 2017 S. Kargozar, S.J. Hashemian, M. Soleimani, P.B. Milan, M. Askari, V. Khalaj, et al. Acceleration of bone regeneration in bioactive glass/gelatin composite scaffolds seeded with bone marrow-derived mesenchymal stem cells over-expressing bone morphogenetic protein-7. Materials Science and Engineering: C, 75 (2017), pp. 688-698.

Kenari, Alinejad et al., 2013 H.S. Kenari, Z. Alinejad, M. Imani, A. Nodehi. Effective parameters in determining cross-linked dextran microsphere characteristics: Screening by Plackett-Burman design-of-experiments. Journal of Microencapsulation, 30 (6) (2013), pp. 599-611.

Kenari, Imani, Dashtimoghadam et al., 2013

H.S. Kenari, M. Imani, E. Dashtimoghadam, A. Maleki, B. Nyström, A. Nodehi. Oscillatory rheometric tracing of dextran crosslinking reaction in aqueous semidilute solutions-Effects of formulation on the gelation properties. Polymer, 54 (12) (2013), pp. 2999-3007.

Kenari, Imani et al., 2013 H.S. Kenari, M. Imani, A. Nodehi. Full factorial design-of-experiments for preparation of crosslinked dextran microspheres. Journal of Applied Polymer Science, 127 (5) (2013), pp. 3712-3724.

Khojasteh et al., 2017 A. Khojasteh, F. Fahimipour, M. Jafarian, D. Sharifi, S. Jahangir, F. Khayyatan, et al. Bone engineering in dog mandible: Coculturing mesenchymal stem cells with endothelial progenitor cells in a composite scaffold containing vascular endothelial growth factor. Journal of Biomedical Materials Research Part B: Applied Biomaterials, 105 (7) (2017), pp. 1767-1777.

Li et al., 2013 J. Li, L. Wei, J. Sun, G. Guan. Effect of ionic products of dicalcium silicate coating on osteoblast differentiation and collagen production via TGF- $\beta 1$ pathway. Journal of Biomaterials Applications, 27 (5) (2013), pp. 595-604.

Liu and Chan-Park, 2009 Y. Liu, M.B. Chan-Park. Hydrogel based on interpenetrating polymer networks of dextran and gelatin for vascular tissue engineering. Biomaterials, 30 (2) (2009), pp. 196-207. 
Liu and Ma, 2004 X. Liu, P.X. Ma. Polymeric scaffolds for bone tissue engineering. Annals of Biomedical Engineering, 32 (3) (2004), pp. 477-486.

Livney et al., 2001 Y.D. Livney, O. Ramon, E. Kesselman, U. Cogan, S. Mizrahi, Y. Cohen. Swelling of dextran gel and osmotic pressure of soluble dextran in the presence of salts. Journal of Polymer Science Part B: Polymer Physics, 39 (22) (2001), pp. 2740-2750.

Lizzi et al., 2017 F. Lizzi, C. Villat, N. Attik, P. Jackson, B. Grosgogeat, C. Goutaudier. Mechanical characteristic and biological behaviour of implanted and restorative bioglasses used in medicine and dentistry: A systematic review. Dental Materials, 33 (6) (2017), pp. 702-712.

Mačković et al., 2012 M. Mačković, A. Hoppe, R. Detsch, D. Mohn, W.J. Stark, E. Spiecker, et al. Bioactive glass (type 45S5) nanoparticles: In vitro reactivity on nanoscale and biocompatibility. Journal of Nanoparticle Research, 14 (7) (2012), p. 966.

Mami et al., 2008 M. Mami, A. Lucas-Girot, H. Oudadesse, R. Dorbez-Sridi, F. Mezahi, E. Dietrich. Investigation of the surface reactivity of a sol-gel derived glass in the ternary system $\mathrm{SiO}_{2}-\mathrm{CaO}-$ $\mathrm{P}_{2} \mathrm{O}_{5}$. Applied Surface Science, 254 (22) (2008), pp. 7386-7393.

Mansur and Costa, 2008 H.S. Mansur, H.S. Costa. Nanostructured poly (vinyl alcohol)/bioactive glass and poly (vinyl alcohol)/chitosan/bioactive glass hybrid scaffolds for biomedical applications. Chemical Engineering Journal, 137 (1) (2008), pp. 72-83.

Maquet et al., 2004 V. Maquet, A.R. Boccaccini, L. Pravata, I. Notingher, R. Jérôme. Porous poly ( $\alpha-$ hydroxyacid)/Bioglass ${ }^{\circledR}$ composite scaffolds for bone tissue engineering. I: Preparation and in vitro characterization. Biomaterials, 25 (18) (2004), pp. 4185-4194.

Mota et al., 2012 J. Mota, N. Yu, S.G. Caridade, G.M. Luz, M.E. Gomes, R.L. Reis, et al. Chitosan/bioactive glass nanoparticle composite membranes for periodontal regeneration. Acta Biomaterialia, 8 (11) (2012), pp. 4173-4180.

Mozafari et al., 2010 M. Mozafari, M. Rabiee, M. Azami, S. Maleknia. Biomimetic formation of apatite on the surface of porous gelatin/bioactive glass nanocomposite scaffolds. Applied Surface Science, 257 (5) (2010), pp. 1740-1749.

Mozafari et al., 2012 M. Mozafari, M. Mehraien, D. Vashaee, L. Tayebi. Electroconductive nanocomposite scaffolds: A new strategy into tissue engineering and regenerative medicine. Nanocomposites-new trends and developments, InTech (2012).

Murugan and Ramakrishna, 2005 R. Murugan, S. Ramakrishna. Development of nanocomposites for bone grafting. Composites Science and Technology, 65 (15) (2005), pp. 2385-2406.

Nadeem et al., 2013 D. Nadeem, M. Kiamehr, X. Yang, B. Su. Fabrication and in vitro evaluation of a sponge-like bioactive-glass/gelatin composite scaffold for bone tissue engineering. Materials Science and Engineering: C, 33 (5) (2013), pp. 2669-2678.

O'brien, 2011 F.J. O'brien. Biomaterials \& scaffolds for tissue engineering. Materials Today, 14 (3) (2011), pp. 88-95.

Patel et al., 2011 H. Patel, M. Bonde, G. Srinivasan. Biodegradable polymer scaffold for tissue engineering. Trends in Biomaterials \& Artificial Organs, 25 (1) (2011), pp. 20-29.

Peter et al., 2009 M. Peter, P.T.S. Kumar, N.S. Binulal, S.V. Nair, H. Tamura, R. Jayakumar. Development of novel $\alpha$-chitin/nanobioactive glass ceramic composite scaffolds for tissue engineering applications. Carbohydrate Polymers, 78 (4) (2009), pp. 926-931.

Peter, Binulal, Nair et al., 2010 M. Peter, N. Binulal, S. Nair, N. Selvamurugan, H. Tamura, R. Jayakumar. Novel biodegradable chitosan-gelatin/nano-bioactive glass ceramic composite scaffolds for alveolar bone tissue engineering. Chemical Engineering Journal, 158 (2) (2010), pp. 353-361. 
Peter, Binulal, Soumya et al., 2010 M. Peter, N. Binulal, S. Soumya, S. Nair, T. Furuike, H. Tamura, et al. Nanocomposite scaffolds of bioactive glass ceramic nanoparticles disseminated chitosan matrix for tissue engineering applications. Carbohydrate Polymers, 79 (2) (2010), pp. 284-289.

Ravarian et al., 2010 R. Ravarian, F. Moztarzadeh, M.S. Hashjin, S. Rabiee, P. Khoshakhlagh, M. Tahriri. Synthesis, characterization and bioactivity investigation of bioglass/hydroxyapatite composite. Ceramics International, 36 (1) (2010), pp. 291-297.

Razavi et al., 2014 M. Razavi, M. Fathi, O. Savabi, S.M. Razavi, F. Heidari, M. Manshaei, et al. In vivo study of nanostructured diopside $\left(\mathrm{CaMgSi}_{2} \mathrm{O}_{6}\right)$ coating on magnesium alloy as biodegradable orthopedic implants. Applied Surface Science, 313 (2014), pp. 60-66.

Roman et al., 2003 J. Roman, S. Padilla, M. Vallet-Regi. Sol-Gel glasses as precursors of bioactive glass ceramics. Chemistry of Materials, 15 (3) (2003), pp. 798-806.

Salimi-Kenari et al., 2016 H. Salimi-Kenari, M. Imani, A. Nodehi, H. Abedini. An engineering approach to design of dextran microgels size fabricated by water/oil emulsification. Journal of Microencapsulation, 33 (6) (2016), pp. 511-523.

Salimi-Kenari et al., 2018 H. Salimi-Kenari, F. Mollaie, E. Dashtimoghadam, M. Imani, B. Nyström. Effects of chain length of the cross-linking agent on rheological and swelling characteristics of dextran hydrogels. Carbohydrate Polymers, 181 (2018), pp. 141-149.

Salinas and Vallet-Regí, 2013 A.J. Salinas, M. Vallet-Regí. Bioactive ceramics: From bone grafts to tissue engineering. RSC Advances, 3 (28) (2013), pp. 11116-11131.

Shamsi et al., 2017 M. Shamsi, M. Karimi, M. Ghollasi, N. Nezafati, M. Shahrousvand, M. Kamali, et al. In vitro proliferation and differentiation of human bone marrow mesenchymal stem cells into osteoblasts on nanocomposite scaffolds based on bioactive glass $\left(64 \mathrm{SiO}_{2}-31 \mathrm{CaO}-5 \mathrm{P}_{2} \mathrm{O}_{5}\right)$-poly-Ilactic acid nanofibers fabricated by electrospinning method. Materials Science and Engineering: C, 78 (2017), pp. 114-123.

Siqueira et al., 2017 R.L. Siqueira, N. Maurmann, D. Burguêz, D.P. Pereira, A.N. Rastelli, O. Peitl, et al. Bioactive gel-glasses with distinctly different compositions: Bioactivity, viability of stem cells and antibiofilm effect against Streptococcus mutans. Materials Science and Engineering: C, 76 (2017), pp. 233-241.

Srinivasan et al., 2012 S. Srinivasan, R. Jayasree, K. Chennazhi, S. Nair, R. Jayakumar. Biocompatible alginate/nano bioactive glass ceramic composite scaffolds for periodontal tissue regeneration. Carbohydrate Polymers, 87 (1) (2012), pp. 274-283.

Tamjid et al., 2011 E. Tamjid, R. Bagheri, M. Vossoughi, A. Simchi. Effect of particle size on the in vitro bioactivity, hydrophilicity and mechanical properties of bioactive glass-reinforced polycaprolactone composites. Materials Science and Engineering: C, 31 (7) (2011), pp. 15261533.

Tousi et al., 2013 N.S. Tousi, M.F. Velten, T.J. Bishop, K.K. Leong, N.S. Barkhordar, G.W. Marshall, et al. Combinatorial effect of $\mathrm{Si}^{4+}, \mathrm{Ca}^{2+}$, and $\mathrm{Mg}^{2+}$ released from bioactive glasses on osteoblast osteocalcin expression and biomineralization. Materials Science and Engineering: $C, 33$ (5) (2013), pp. 2757-2765.

Van Vlierberghe et al., 2011 S. Van Vlierberghe, P. Dubruel, E. Schacht. Biopolymer-based hydrogels as scaffolds for tissue engineering applications: A review. Biomacromolecules, 12 (5) (2011), pp. 1387-1408.

Varoni et al., 2010 E. Varoni, E. Canciani, B. Palazzo, V. Betti, C. Dellavia, L. Rimondini. Nanostructured hydroxyapatite-dextran composite scaffolds for tissue engineering. Dental Materials, 26 (2010), pp. e83-e84. 
Wu et al., 2013 C. Wu, Y. Zhou, J. Chang, Y. Xiao. Delivery of dimethyloxallyl glycine in mesoporous bioactive glass scaffolds to improve angiogenesis and osteogenesis of human bone marrow stromal cells. Acta Biomaterialia, 9 (11) (2013), pp. 9159-9168.

Wu et al., 2017 J. Wu, Z. Wu, Z. Xue, H. Li, J. Liu. PHBV/bioglass composite scaffolds with co-cultures of endothelial cells and bone marrow stromal cells improve vascularization and osteogenesis for bone tissue engineering. RSC Advances, 7 (36) (2017), pp. 22197-22207.

Yazdimamaghani et al., 2013 M. Yazdimamaghani, T. Pourvala, E. Motamedi, B. Fathi, D. Vashaee, L. Tayebi. Synthesis and characterization of encapsulated nanosilica particles with an acrylic copolymer by in situ emulsion polymerization using thermoresponsive nonionic surfactant. Materials, 6 (9) (2013), pp. 3727-3741.

Yazdimamaghani et al., 2014 M. Yazdimamaghani, D. Vashaee, S. Assefa, M. Shabrangharehdasht, A.T. Rad, M.A. Eastman, et al. Green synthesis of a new gelatin-based antimicrobial scaffold for tissue engineering. Materials Science and Engineering: C, 39 (2014), pp. 235-244.

Yazdimamaghani et al., 2015 M. Yazdimamaghani, M. Razavi, D. Vashaee, V.R. Pothineni, J. Rajadas, L. Tayebi. Significant degradability enhancement in multilayer coating of polycaprolactonebioactive glass/gelatin-bioactive glass on magnesium scaffold for tissue engineering applications. Applied Surface Science, 338 (2015), pp. 137-145. 